At f 6a def i ci ency suppresses mi crogl i al act $i$ vat $i$ on and amel i or at es pat hol ogy of exper i ment al aut oi mmine encephal onyel i t i s

\begin{tabular}{|c|c|}
\hline 著者 & タヒウミン \\
\hline 著者別表示 & Ta H eu M nh \\
\hline $\begin{array}{l}\text { j our nal or } \\
\text { publ i cat } i \text { on } t i t l e\end{array}$ & 博士論文本文Ful I \\
\hline 学位授与番号 & 13301甲第4459号 \\
\hline 学位名 & 博士 (医学) \\
\hline 学位授与年月日 & $2016-09-26$ \\
\hline URL & ht t p: //hdl . handl e. net /2297/46469 \\
\hline
\end{tabular}




\title{
Atf6 $\alpha$ deficiency suppresses microglial activation and ameliorates pathology of experimental autoimmune encephalomyelitis
}

Hieu Minh $\mathrm{Ta}^{1}$, Thuong Manh Le ${ }^{1}$, Hiroshi Ishii ${ }^{1}$, Mika Takarada-Iemata ${ }^{1}$, Tsuyoshi Hattori ${ }^{1}$, Koji Hashida ${ }^{1}$, Yasuhiko Yamamoto ${ }^{2}$, Kazutoshi Mori ${ }^{3}$, Ryosuke Takahashi ${ }^{4}$, Yasuko Kitao ${ }^{1}$, Osamu Hori ${ }^{1^{*}}$

${ }^{1}$ Department of Neuroanatomy, Graduate School of Medical Sciences, Kanazawa University

${ }^{2}$.Department of Biochemistry and Molecular Vascular Biology, Graduate School of Medical Sciences, Kanazawa University

${ }^{3}$ Department of Biophysics, Graduate School of Science, Kyoto University,

${ }^{4}$ Department of Neurology, Graduate School of Medicine, Kyoto University

* Corresponding Author:

Dr. Osamu Hori

Department of Neuroanatomy, Kanazawa University Graduate School of Medical Sciences, 13-1 Takara-Machi, Kanazawa City,

Ishikawa 920-8640, Japan

TEL: +81-76-265-2162

FAX: $+81-76-234-4222$

E-mail: osamuh3@staff.kanazawa-u.ac.jp

Running title: ATF6 $\alpha$ and CNS inflammation

Keywords: multiple sclerosis, microglia, UPR, inflammation

\begin{abstract}
Abbreviations: ATF4, activating transcription factor 4; ATF6 $\alpha$, activating transcription factor $6 \alpha$; BMT, Bone marrow transfer; CHOP, C/EBP homologous protein; CNS, central nervous system; EAE, experimental autoimmune encephalomyelitis; eIF2 $\alpha$, eukaryotic translation initiation factor 2; ER, endoplasmic reticulum; GFAP, Glial fibrillary acidic protein; GRP78, glucose-regulated protein78; GRP94, glucose-regulated protein94; H\&E, hematoxylin-eosin; Ire $1 \alpha$, inositol-requiring enzyme $1 \alpha$; IFN- $\gamma$, interferon- $\gamma$; MAPK, mitogen-activated protein kinase, MS, multiple sclerosis; PERK, Protein kinase R (PKR)-like endoplasmic reticulum kinase; PMW, Pelizaeus-Merzbacher Disease; PLP1, proteolipid protein-1; TLR4, Toll-like receptor 4; UPR, unfolded protein response
\end{abstract}




\section{Abstract}

Accumulating evidence suggests a critical role for the unfolded protein response (UPR) in multiple sclerosis (MS) and in its animal model, experimental autoimmune encephalomyelitis (EAE). In this study, we investigated the relevance of activating transcription factor $6 \alpha(\mathrm{ATF} 6 \alpha)$, an upstream regulator of part of the UPR, in EAE. The expressions of ATF6 $\alpha$-target molecular chaperones such as glucose-regulated protein 78 (GRP78) and glucose-regulated protein 94 (GRP94) were enhanced in the acute inflammatory phase after induction of EAE. Deletion of Atf6 $\alpha$ suppressed the accumulation of T cells and microglia/macrophages in the spinal cord, and ameliorated the clinical course and demyelination after EAE induction. In contrast to the phenotypes in the spinal cord, activation status of $\mathrm{T}$ cells in the peripheral tissues or in the culture system was not different between two genotypes. Bone marrow transfer (BMT) experiments and adoptive transfer of autoimmune $\mathrm{CD}^{+} \mathrm{T}$ cells to recipient mice (passive EAE) also revealed that CNS-resident cells are responsible for the phenotypes observed in $A t f 6 \alpha^{-/-}$mice. Further experiments with cultured cells indicated that inflammatory response was reduced in Atf6 $\alpha^{-/-}$microglia, but not in Atf $6 \alpha^{-/-}$ astrocytes, and was associated with proteasome-dependent degradation of NF-kB p65. Thus, our results demonstrate a novel role for ATF6 $\alpha$ in microglia-mediated CNS inflammation. 


\section{Introduction}

Multiple sclerosis (MS) is the most common autoimmune disease of the central nervous system (CNS) that affects approximately 2.5 million people worldwide (Compston et al., 2008). Both MS and its well-studied murine model, experimental autoimmune encephalomyelitis (EAE), are characterized by extensive immune cell infiltration leading to inflammation, gliosis, demyelination, and eventual neurodegeneration (Dendrou et al., 2015). MS/EAE is mediated by activated autoreactive myelin-specific $\mathrm{CD}^{+} \mathrm{T}$ cells that enter the CNS. However, recent evidence has suggested that a broader range of cells from both the innate and adaptive immune systems, as well as glial cells in the CNS, may contribute to the development of its pathology (Duffy et al, 2014). Among these, resident-microglia and infiltrating macrophages produce a plethora of neurotoxic inflammatory mediators such as cytokines, chemokines, and reactive oxygen species, and are now considered as key players in MS/EAE pathogenesis (Friese et al., 2014; Xiao et al., 2013).

It is well-documented that under conditions such as inflammation, cells show rapidly increased rates of protein synthesis, resulting in the accumulation of unfolded proteins in the endoplasmic reticulum (ER) (Zhang and Kaufman, 2008; Kitamura, 2011). This buildup of unfolded proteins results in ER stress and activates the unfolded protein response (UPR). The UPR is composed of three transducers: Protein kinase R (PKR)-like endoplasmic reticulum kinase (PERK), inositol-requiring enzyme $1 \alpha$ (Ire $1 \alpha$ ), and activating transcription factor $6 \alpha$ (ATF6 $\alpha$ ) (Mori, 2009; Walter and Ron, 2011). PERK-downstream events include phosphorylation of the alpha subunit of eukaryotic translation initiation factor 2 (eIF2 $\alpha$ ), which suppresses global protein synthesis to reduce protein loads into the ER and paradoxically enhances the translation of activating transcription factor 4 (ATF4), which upregulates the expression of $\mathrm{C} / \mathrm{EBP}$ homologous protein $(\mathrm{CHOP})$. In contrast, the downstream molecules of 
IRE1 $\alpha$ and ATF6 $\alpha$ include molecular chaperones in the ER, such as glucose-regulated protein78 (GRP78) and glucose-regulated protein 94 (GRP94).

Accumulating evidence has suggested a crucial role for the UPR in the pathogenesis of various myelin disorders including MS, Pelizaeus-Merzbacher Disease (PMD), and their animal models (for review, Lin and Popko, 2009; Stone and Lin, 2015). PMD is an X chromosome -linked demyelinating disease which is caused by mutations in the gene proteolipid protein-1 (PLP1). Activation of the UPR was observed in the white matter of PMD patient and PLP1-mutant mice, and also in the transfected fibroblasts expressing mutant protein (Southwood et al., 2002). Interestingly, the CHOP protein, which had been known as a pro-apoptotic transcription factor, exhibited protective activity on the oligodendrocytes in the PLP1-mutant mice (Southwood et al., 2002). Consistent with the observations in PMD, enhanced level of the UPR marker proteins was observed in multiple cell types of both MS patients (Mháille, et al., 2008) and EAE mice (Ni Fhlathartaigh, et al., 2013). Recent studies have further demonstrated important roles for PERK on oligodendrocytes. Differential effects of interferon- $\gamma($ IFN- $\gamma)$ on demyelination were mediated, at least in part, by activation of PERK-eIF2 $\alpha$ pathway in oligodendrocytes (Lin et al., 2006; Lin et al., 2007). Moderate PERK activation was protective on oligodendrocytes in the models of MS (Lin et al., 2013; Lin et al., 2014), and, consistently, oligodendrocyte-specific PERK deletion increased the susceptibility of mice to EAE (Hussien et al., 2014). Although the importance of the PERK pathway in MS/EAE is being revealed, the role of other UPR pathways remains unknown.

In the current study, we sought to dissect the role of ATF6 $\alpha$ during EAE pathogenesis. We found that the ATF6 $\alpha$ pathway is activated in the spinal cords at the acute phase of EAE. Surprisingly, deletion of Atf6 $\alpha$ ameliorated demyelination, inflammation, and EAE severity. Atf6 $\alpha$ deficiency did not affect immune response in the peripheral tissues, but repressed microglia-mediated inflammation. The mechanism may include proteasome-dependent 
degradation of NF- $\kappa$ B p65 in microglia. Our data indicate for the first time that ATF6 $\alpha$ is crucial for microglial activation and pathogenesis in EAE. 


\section{Materials and Methods}

Mice and induction of EAE All animal experiments were approved by the Animal Care and Use Committee of Kanazawa University (AP-153485). Atf6 $\alpha^{+/-}$mice were generated as previously described (Yamamoto et al. 2007), and backcrossed with the C57BL/6 strain more than 8 times in the Institute of Laboratory Animals Graduate School of Medicine, Kyoto University. Atf6 $\alpha^{+/-}$mice were then intercrossed to obtain Wild-type (WT) and Atf6 $\alpha^{-/-}$mice, and maintained by mating mice with same genotypes (WT male and WT female mice, or Atf6 $\alpha^{-/-}$male and Atf6 $\alpha^{-/-}$female mice) in the Institute for experimental animals, Kanazawa University Advanced science research center.

Male mice (aged 7-10 weeks and weighing 20-25 g) were used for the experiments. GFP transgenic mice in the C57BL/6 strain were kindly provided by Dr. Ikawa from Osaka University, Japan (Okabe et al., 1997). Active and passive EAE were induced in mice as described preciously (Stromnes and Goverman, 2006A; Stromnes and Goverman, 2006B). For active EAE, mice were subcutaneously injected with $200 \mu$ of an emulsion (1:1 ratio of PBS

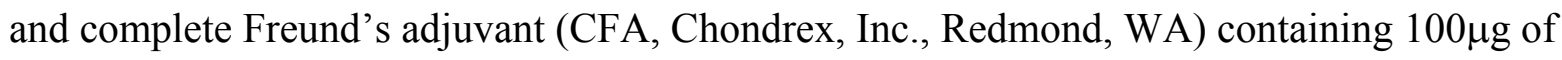
myelin oligodendrocyte glycoprotein peptide 35-55 (MOG $35-55)$ (GL Biochem (Shanghai) Ltd., Shanghai, China). At $0 \mathrm{~h}$ and $48 \mathrm{~h}$ after immunization, mice were intraperitoneally injected with $200 \mathrm{ng}$ of pertussis toxin (List Biological Laboratories, Campbell, CA). Samples from the acute and chronic phases were taken from day 14 to 17 and from day 40 to 50 after induction of EAE, respectively. For adoptive transfer of autoimmune $\mathrm{CD}^{+}$cells to recipient mice (passive EAE), mice were immunized with $\mathrm{MOG}_{35-55}$ peptide in $\mathrm{CFA}$, and at day 9, the spleen and draining lymph nodes (inguinal, proper axillary and accessory axillary) were harvested. The

pooled cells $\left(3-4 \times 10^{6}\right.$ cells $\left./ \mathrm{ml}\right)$ were restimulated with $20 \mu \mathrm{g} / \mathrm{ml}$ of MOG, and IL-2 (40 U/ml, R\&D Systems, Inc., Minneapolis, USA) was added at $48 \mathrm{~h}$ after the restimulation. After $24 \mathrm{~h}$ 
incubation, $\mathrm{CD} 4^{+}$cells were isolated by negative selection using the $\mathrm{CD} 4^{+}$cells isolation kit (Miltenyi Biotec GmbH, Bergisch Gladbach, Germany). These cells $\left(7 \times 10^{6}\right.$ cells $\left./ 250 \mu 1 \mathrm{PBS}\right)$ were intravenously injected into sublethally irradiated (480 Gy) mice. Mice were scored for clinical severity, as previously described (Miller et al., 2010). Score $0=$ normal, Score $1=\operatorname{limp}$ tail or hind limb weakness, but not both, Score $2=$ limp tail and hind limb weakness, Score $3=$ partial hind limb paralysis, Score $4=$ complete hind limb paralysis, Score $5=$ moribund or death by EAE.

Bone marrow transfer (BMT) Bone marrow chimeras were generated as described previously (Xiao et al., 2013). In brief, mice were lethally irradiated (9.8 Gy, $0.5 \mathrm{~Gy} / \mathrm{min}$ ), and after $20 \mathrm{~h}$, bone marrow cells $\left(10^{7}\right.$ cells $\left./ 100 \mu \mathrm{l}\right)$ derived from GFP-transgenic mice, were infused by intravenous injection. After 8 weeks, the chimeric mice were induced for active EAE as described above.

Isolation of mononuclear cells from tissues Mononuclear cells from the spleen and lymph nodes were prepared by homogenizing tissues through a cell strainer (BD, Franklin Lakes, NJ), followed by treatment with ACK lysing buffer (Thermo Fisher Scientific, Waltham, MA). Mononuclear cells from the brain and spinal cord were isolated as described previously (Schattling et al., 2012). In brief, mice were perfused with HBSS, and the brain and spinal cord were removed. They were minced and digested in collagenase (Sigma, St. Louis, MO) solution containing DNAseI (Sigma) for $45 \mathrm{~min}$ at $37^{\circ} \mathrm{C}$. After triturating through the cell strainer (BD), the tissue was resuspended in $30 \%$ of Percoll (GE Healthcare, Little Chalfont, Buckinghamshire, UK) and layered underneath 70\% Percoll. After centrifugation $(1,500 \mathrm{~g}, 30$ min), cells were harvested from the interface. 
staining the cells with monoclonal antibodies against the following proteins: CD3e (145-2C11, 1:100; eBioscience, San Diego, CA), CD4 (GK1.5, 1:100; Tonbo Bioscience, San Diego, CA), CD8a (53-6.7, 1:100; eBioscience), CD11b (M1/70, 1:100; Biolegend, San Diego, CA), B220 (RA3-6B2, 1:100; BD), CD45 (30-F11, 1:100; eBioscience), IFN- $\gamma$ (XMG1.2, 1:100; eBioscience), IL-17A (eBio17B7, 1:100; eBioscience), TNF $\alpha$ (MP6-XT22, 1:100; eBioscience), and NOS2 (CXNFT, 1:100; eBioscience). Intracellular cytokine staining was performed as described previously (Jäger et al., 2009). In brief, cells were stimulated for $4.5 \mathrm{~h}$ with $50 \mathrm{ng} / \mathrm{ml}$ PMA (Sigma) and $1 \mu \mathrm{M}$ ionomycin (Sigma) in the presence of GolgiStop (BD). Cells were then fixed and permeabilized using the Intracellular Fixation and Permeabilization Buffer Set (eBioscience). Cells were analyzed for cytokine production by staining with anti-cytokine Abs. Flow cytometry was performed using the Gallios ${ }^{\mathrm{TM}}$ flow cytometer (Beckman Coulter, Indianapolis IN), and data were analyzed using the Kaluza software (Beckman Coulter) or Flowjo software (Tree Star, Ashland, OR). Cell proliferation was measured as described previously (Muramatsu et al., 2011). In brief, on day 10 after EAE induction, splenocytes and lymphocytes were isolated from the spleen and lymph node, respectively. Cells were re-stimulated with $\mathrm{MOG}_{35-55}$ for 3 days, and then subjected to the BrdU incorporation assay (CycLex Co., LTD, Nagano, Japan). lumbar spinal cord of each mouse using RNeasy ${ }^{\circledR}$ Lipid Tissue Mini Kit (Qiagen, Valencia, CA), and from cultured microglia or astrocytes using the RNeasy ${ }^{\circledR}$ mini Kit (Qiagen). RT reactions containing $1 \mu \mathrm{g}$ of total RNA were performed using PrimeScript ${ }^{\mathrm{TM}}$ (Takara, Otsu, Shiga, Japan). Individual cDNA was amplified with THUNDERBIRD ${ }^{\mathrm{TM}} \mathrm{SYBR}_{\mathrm{qPCR}}{ }^{\circledR} \mathrm{Mix}$ (TOYOBO CO, LTD, Osaka, Japan) by using specific primers for Atf6a, Ddit3 (CHOP), sXbpl, 
Nos2 (iNOS), Ccl2, Ccl8, Mmp9, and Gapdh, as described below. The comparative Ct method was used for data analyses with MxPro 4.10 (Agilent Technologies, Santa Clara, CA). Values for each gene were normalized to Gapdh expression levels. Primer sequences for qPCR: Atf6 $\alpha$, GTCTCATTTCGAAGGGATCAT and AGTCCTGCCCATTGATCACA; $s \times b p-1$, TAGAAAGAAAGCCCGGATGA and CTCTGGGGAAGGACATTTGA; Hspa5, ATGGTATTCTCCGAGTGACA and GCTTTCCAGCCATTCAATCT; Nos 2

AGAATGTGACCATCATGGAC and GAGGGACCAGCCAAATCCAGT; Ccl2

CCAGCAAGATGATCCCAATG and TCTGGACCCATTCCTTCTTG; Ccl8 AGCCTTGAACCTTCACACCTGAGT and CCAGGCACCATCTGCTTGTAACAT; Gapdh AGGTCGGTGTGAACGGATTTG and TGTAGACCATGTAGTTGAGGTCA

Western blot $\quad$ Samples from the lumbar spinal cords or from cultured cells were solubilized in a buffer containing $1 \%$ NP40, $0.1 \%$ SDS, and $0.2 \%$ deoxycholate. Solubilized samples were subjected to western blotting with the following antibodies: KDEL (StressGen, Victoria, British Columbia, Canada), p38 (StressMarq Biosciences Inc., Victoria, BC, Canada), JNK (Santa Cruz Biotechnology, Inc., Dallas, TX), p-JNK, p-p38, ERK1/2, p-ERK1/2, p65, p-p65, IкB $\alpha$, and p-IKK $\alpha / \beta$ (Cell signaling technology, Danvers, MA), GAPDH (Wako, Osaka City, Osaka, Japan). Primary antibody binding was visualized using the ECL system (GE Healthcare Bio-Sciences Corp., Piscataway, NJ).

Histology and immunohistochemistry Lumbar spinal cords were dissected from mice after perfusion with $4 \%$ paraformaldehyde, and cross-sections $(10-\mu \mathrm{m}$ thick for cryosections and $4-\mu \mathrm{m}$ thick for paraffin sections) were cut on a cryostat or a microtome. Sections were processed for hematoxylin-eosin (H\&E) staining or for immunohistochemistry with the following antibodies: KDEL (StressGen), NeuN, APC, MBP (Millipore, Billerica, MA), 
GFAP (Dako, Glostrup, Denmark), Iba1 (Wako), CD45, CD4 (BD), p65, and GFP (MBL, Nagoya City, Aichi, Japan). In some cases, cell nuclei were visualized with DAPI (Sigma). Cy3-labeled- and Alexa 488-labeled-IgG were used as secondary antibodies. Confocal images were obtained by using Nikkon EZ-C1.

Cell culture Microglia and astrocytes were isolated from the cerebral cortex of 1-3-d-old neonatal mice following previously described methods with minor modifications (McCarthy and Vellis, 1980; Giulian and Baker, 1985). Briefly, cerebral hemispheres were harvested from neonatal mice, and the meninges were carefully removed. Brain tissue was then digested at $37^{\circ} \mathrm{C}$ in HEPES-buffered saline containing Dispase II ( $2 \mathrm{mg} / \mathrm{mL}$; Wako). Cells were resuspended in DMEM (Sigma) supplemented with 10\% fetal bovine serum, and plated in T75 culture flasks (Corning Inc., Corning, NY) at the density of two brains/flask. After a 10-d cultivation period, microglia and astrocytes were separated by shaking (200 rpm, $20 \mathrm{~h}$ ). Microglia were harvested from the floating cell populations, and plated at a density of $8 \times 10^{4}$ cells/well in 8 chamber slides (WATSON CO., Kobe, Hyogo, Japan) or $6 \times 10^{5}$ cells/well in 6 well culture plates (Corning Inc.). Astrocytes were obtained from adherent cell populations, and plated at a density of $5 \times 10^{5}$ cells/well in 6 well culture plates. The isolated microglia and astrocytes were used for experiments after $24 \mathrm{~h}$ incubation and after achieving confluence, respectively. Cells were treated with LPS (100 ng/ml; Sigma), IL-1 $\beta$ (100 ng/ml; Wako) or $\mathrm{TNF} \alpha(20 \mathrm{ng} / \mathrm{ml}$; Wako) for the indicated times. In some cases, cells were also treated with MG132 (10 $\mu \mathrm{M}$; Sigma), a proteasomal inhibitor for the indicated times. described (Goldmann et al., 2013). Briefly, cultured microglia in 8 chamber slides were stimulated with LPS, IL-1 $\beta$ or TNF $\alpha$ or maintained in the medium alone, and then fixed with 
$4 \%$ paraformaldehyde containing $0.2 \%$ of NP-40. Cells were subjected to immunocytochemistry with antibodies against Iba1 and p65. Cell nuclei were visualized with DAPI (Sigma). Confocal images were obtained by using Nikkon EZ-C1.

\section{$N F-\kappa B$ transcription activity $\quad$ Activation status of NF- $\kappa \mathrm{B}$ was measured using} TransAM ${ }^{\circledR}$ NFkB p65 Chemi Kit (Active motif, Carlsbad, CA)(Renard et al., 2001). Briefly, nuclear extract was performed using cultured microglia stimulated with LPS or maintained in the medium alone, according to the manufacture's protocol. Nuclear proteins $(10 \mu \mathrm{g})$ were added to a 96 well plate containing an immobilized oligonucleotide corresponding site (5'-GGGACTTTCC-3'). After $1 \mathrm{~h}$ incubation at room temperature, an antibody against an epitope of the p65 subunit of NF- $\kappa \mathrm{B}$ was added, and incubated again for $1 \mathrm{~h}$ at room temparature. Further incubation with peroxidase-conjugated secondary antibody and with a developing solution resulted in chemiluminescence. Positive and negative control were made using a nuclear extract of Jurkat cells provided by the manufacture and through competitive binding with a wild-type consensus sequence, also provided by the manufacture. The addition of a mutant consensus oligonucleotide did not have any effect on NF- $\kappa \mathrm{B}$ binding.

\section{Image Quantification and statistical analysis Quantification of western blots,} immunohistochemistry and immunocytochemistry images was performed using Image J. To quantify demyelination, the MBP-negative area in each section was measured at 10x magnification, and calculated as percentage of entire section area. The number of microglia/macrophage was counted for cells with $\mathrm{Ibal}^{+}$and $\mathrm{DAPI}^{+}$images. Evaluation of the nuclear fluorescence in cultured microglia was performed as previously described (McCloy et al., 2014), using the total corrected cellular fluorescence (TCCF) which was calculated by formula: TCCF=Integrated Density-(Area of selected cell x Mean fluorescence of background 
readings). Statistical analyses were performed using the Student's t-test or analysis of variance (ANOVA). The level of significance was chosen as $\mathrm{P} \leq 0.05$ 


\section{Results}

ATF6 $\alpha$ pathway is activated at the acute phase of EAE.

We first evaluated the activation status of the UPR during the time course of EAE. qRT-PCR analysis revealed that Atf6 $\alpha$ expression increased and reached a peak at the acute phase of EAE (Fig. 1A). Similarly, the expression of spliced $X b p 1$, which encodes the activated form of XBP1, a transcription factor in the IRE1 pathway operating in concert with ATF6 $\alpha$ to regulate the downstream genes such as molecular chaperones, ERAD and membrane synthesizing proteins, also increased at this period. In contrast, the expression of Ddit3 (CHOP), a downstream molecule of PERK, was elevated at the chronic phase of EAE (Fig. 1A). These data indicate that all three branches of the UPR are activated after EAE, even though their contribution to EAE pathogenesis might be different (Fig. 1A). Western blot analysis confirmed the peak of the expression of ATF6 $\alpha$-target molecules such as GRP94 and GRP78 in the acute phase of EAE (Fig. 1B, Fig. S1).

Molecular chaperones in the ER including GRP78 and GRP94 have a common KDEL amino acid sequence at their C-terminals, and the anti-KDEL antibody has been used to analyze their expression (Takano et al., 2007; Kezuka et al., 2015). In order to determine the activation status of ATF6 $\alpha$ in EAE lesions, we performed immunohistochemistry for KDEL (Fig. 1C), together with that for cell-specific markers (Fig. 1D). In normal (control) condition, KDEL expression was observed predominantly in the gray matter (Fig. 1C). However, once mice were induced with EAE (acute phase), high level of KDEL expression was observed in the white matter (Fig. 1C). KDEL-expressing cells in the control condition included neurons (data not shown) and oligodendrocytes (Fig. 1D), while those in the EAE condition included various cell types such as $\mathrm{CD} 4^{+} \mathrm{T}$ cells, microglia/macrophages, astrocytes and 
oligodendrocytes in the white matter (Fig. 1D), as previously reported (Ni Fhlathartaigh, et al., 2013).

Atf6a deficiency ameliorates EAE severity.

To investigate whether Atf $6 \alpha$ plays a role in the pathogenesis of EAE, we compared phenotypes between wild-type (WT) and Atf6 $\alpha^{-/-}$mice after induction of EAE. In the physiological condition, there was no gross difference between WT and Atf6 $\alpha^{-/-}$mice in the spinal cord (data not shown). However, after induction of EAE, Atf $6 \alpha^{-/-}$mice developed milder clinical symptoms that were characterized by a decrease in the score of paralysis (Fig. 2A). All 12 WT mice and 12 out of 13 Atf $6 \alpha^{-/-}$mice (92.3\%) developed EAE, and 3 out of 12 WT mice (24\%) and 1 out of $13 \mathrm{Atf} 6 \alpha^{-/-}$mice (7.7\%) died in the acute phase of EAE. Consistent with the clinical scores, histological and immunohistochemical analysis revealed that the infiltration level of inflammatory cells and demyelination was lower in the spinal cord of Atf6 $\alpha^{-/-}$mice, compared with that of WT mice (Fig. 2B, C, S5). Flow cytometry analysis demonstrated that this phenotype in $A t f 6 \alpha^{-/-}$mice was associated with a lower number of CNS (brain and spinal cord)-infiltrating $\mathrm{CD}^{+}$and $\mathrm{CD}^{+} \mathrm{T}$ cells (Fig. 2D). In addition, among the $\mathrm{CD} 4^{+} \mathrm{T}$ cells, the number of pathogenic $\mathrm{T}_{\mathrm{H}} 1\left(\mathrm{IFN}-\gamma^{+}\right)$cells were lower in the CNS of Atf6 $\alpha^{-/-}$mice, although that of $\mathrm{T}_{\mathrm{H}} 17$ (IL-17 $\mathrm{A}^{+}$) cells was not significantly different between two genotypes (Fig. 2E, F).

Activation of T cells is not affected by Atf6 $\alpha$ deficiency in the peripheral tissues or in the culture system.

The efficient activation of T cells is critical for induction of EAE. To study whether deletion of Atf $6 \alpha$ affects this, we characterized peripheral lymphocytes in both genotypes. Interestingly, there was no significant difference between WT and $A t f 6 \alpha^{-/}$mice in the number of lymphocyte subsets, including $\mathrm{CD} 4^{+} \mathrm{T}$ cells, $\mathrm{CD} 8^{+} \mathrm{T}$ cells, B220 ${ }^{+} \mathrm{B}$ cells (Fig. S2 A), and 
pathogenic $\mathrm{T}_{\mathrm{H}} 1$ and $\mathrm{T}_{\mathrm{H}} 17$ cells (Fig. $\mathrm{S} 2 \mathrm{~B}$ ) either in the spleen or in the lymph nodes after $\mathrm{EAE}$ induction. We further isolated lymphocytes from immunized mice and tested the in vitro recall response upon secondary exposure to $\mathrm{MOG}_{35-55}$ peptide. T cells derived from Atf6 $^{-/-}$mice did not show an impaired recall response to $\mathrm{MOG}_{35-55}$ compared to WT mice, as assessed by measurement of proliferation (Fig. S3 C). These data suggested that deletion of Atf $6 \alpha$ does not impair T cell activation.

Activation of microglia/macrophages is impaired in Atf6 $\alpha^{-/-}$mice after EAE.

Ample evidence has demonstrated that gliosis is one of the earliest signs of EAE and correlates strongly with the recruitment of immune cells, demyelination, and clinical severity (Davalos et al., 2012). Therefore, we examined whether deletion of Atf6 $\alpha$ caused any changes in microgliosis and astrogliosis after EAE induction. Immunohistochemical analysis of the spinal cord revealed no gross morphological differences between WT and Atf $6 \alpha^{-/-}$mice in the resting microglia under control conditions (Fig. 3A, Control). These types of microglia are characterized by small cell bodies with long, thin ramified processes. After EAE induction, however, either the activated microglia or infiltrating macrophages, which are defined as enlarged cell bodies with short and thick processes, were observed to a lesser extent in the white matter of the spinal cord in $A t f 6 \alpha^{-/-}$mice (Fig. 3A, EAE). In contrast, we observed similar levels of astroglial activation, which was characterized by enlarged cell bodies with thick processes, after EAE in both WT and Atf6 $\alpha^{-/-}$mice (Fig. S3 A).

Activated microglia/macrophages contribute to inflammation, demyelination, and neuronal damage in EAE by releasing a number of potentially toxic substances, including nitric oxide (NO) synthesized by inducible nitric oxide synthase (iNOS, also known as NOS2, Lowenstein et al., 2004). Therefore, we next investigated NOS2 expression levels in the CNS of WT and $A t f 6 \alpha^{-/-}$mice at the acute phase of EAE. Flow cytometry analysis revealed that 


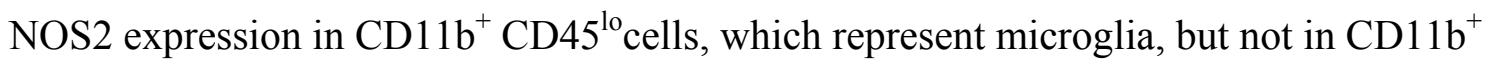
$\mathrm{CD} 45^{\mathrm{hi}}$ cells, which represent invading macrophages, was significantly lower in $\mathrm{Atf} 6 \alpha^{-/-}$mice compared with WT mice after EAE induction (Fig. 3B). Consistent with these data, we found significantly lower levels of $\mathrm{p} 65$ subunit of $\mathrm{NF}-\kappa \mathrm{B}$, a major transcription factor required for NOS2 expression, in the microglia/macrophages from $A t f 6 \alpha^{-/-}$mice (Fig. 3C).

ATF6 $\alpha$ in the CNS-resident cells regulates EAE severity.

In order to analyze whether ATF6 $\alpha$ in the CNS-resident cells plays an essential role in regulating EAE severity, we employed the radiation bone marrow chimeric mice (termed here as BM chimera) and the transfer of WT- and Atf6 $\alpha$-deficient- CD4 ${ }^{+}$T cells to WT mice (passive EAE). BM chimeras were generated by reconstituting lethally irradiated WT or Atf6 $\alpha^{-/-}$mice with WT bone marrow cells isolated from GFP-transgenic mice. In BM chimeras, the peripheral immune system is comprised entirely of BM-donor-derived cells, whereas all CNS-resident microglia remain of host-origin because microglia do not turnover after irradiation and BM reconstitution (Hickey et al., 1992). Our results revealed that lack of Atf6 $\alpha$ expression within the CNS $\left(\mathrm{GFP}^{+} \mathrm{WT} \rightarrow A t f 6 \alpha^{--}\right)$indeed decreased EAE severity compared to chimeric mice that express $A t f 6 \alpha$ in resident $\mathrm{CNS}$ cells $\left(\mathrm{GFP}^{+} \mathrm{WT} \rightarrow \mathrm{WT}\right)($ Fig. 4A). This milder phenotype correlated with a lower level of infiltration of GFP-positive BM-donor-derived cells

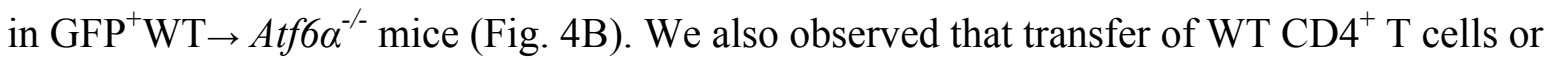
Atf6 $\alpha$-deficient $\mathrm{CD}^{+}$T cells to WT mice (passive EAE) resulted in similar clinical scores (Fig. 4C) and histological phenotypes (Fig. 4D). These data support a role for Atf6 $\alpha$ in CNS-resident cells in mediating EAE severity.

Inflammatory response is impaired in cultured Atf6 $\alpha^{-/-}$microglia 
It is well known that after ligand binding, toll- like receptor 4 (TLR4) recruits several adaptors to trigger inflammatory signaling cascades such as NF- $\kappa \mathrm{B}$ and Mitogen-activated protein kinase (MAPK) pathways (Kawai and Akira, 2007). To investigate whether or not these pathways were affected in Atf $6 \alpha^{-/-}$microglia, we challenged cultured microglia with lipopolysaccharide (LPS), a potent TLR4 ligand. Western blot analysis revealed that, in the NF- $\kappa$ B pathway, the level of both phosphorylated p65 (p-p65) and p65 were significantly lower in Atf6 $\alpha^{-/-}$microglia (Fig. 5A). Of note, the effect of Atf6 $\alpha$ deletion was somewhat larger in the presence of LPS. In contrast, expression of the upstream molecules, such as phosphorylated IKK $\alpha / \beta(\mathrm{p}-\mathrm{IKK} \alpha / \beta)$ and I $\mathrm{B} \mathrm{B} \alpha$, were not different between the two genotypes (Fig. 6A), suggesting that p65 may be a direct target of ATF6 $\alpha$. In MAPK pathways, by contrast, the expression of phosphorylated p38 (p-p38) and phosphorylated ERK1/2 (p-ERK1/2) were only slightly reduced at the later phase after LPS stimulation (at 60 and 90 minutes) in $A t f 6 \alpha^{-/-}$microglia (Fig. S4). There was no significant difference in the expression of phosphorylated JNK (p-JNK) between the two genotypes (Fig. S4). The steady state level of p38, ERK1/2 or JNK was not different between two genotypes, suggesting that the stability of these molecules was not affected by Atf6 $\alpha$ deficiency.

Consistent with these results, the level of NF-kB p65 in the nucleus was lower in Atf $6 \alpha^{-/-}$microglia than in WT microglia after treatment with LPS, or with other NF- $\mathrm{B}$ activators such as IL-1 $\beta$ and TNF $\alpha$ (Fig. 5B, C). It is known that TNF $\alpha$ is released from pathological $\mathrm{T}_{\mathrm{H}} 1 / \mathrm{T}_{\mathrm{H}} 17$ cells, and IL-1 $\beta$ is involved in $\mathrm{T}_{\mathrm{H}} 17$ differentiation, $\mathrm{T}$ cell trafficking and CNS tissue damage during the course of EAE (Rodgers and Miller, 2012). Furthermore, the binding of NF- $\mathrm{KB}$ to its consensus DNA sequence was observed to a lesser extent in Atf $6 \alpha^{-/-}$ microglia, compared with WT microglia after LPS stimulation (Fig. 5D). Finally, upon LPS

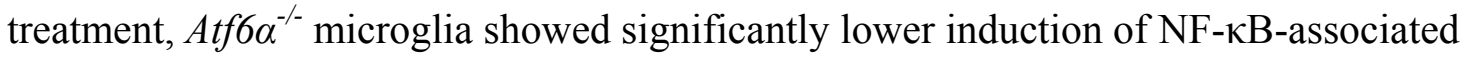
proinflammatory genes such as $\mathrm{Nos} 2, \mathrm{Ccl} 2$, and $C \mathrm{cl} 8$ compared with WT microglia (Fig. 5E). 
As proinflammatory genes can be induced by the synergistic effect of LPS and IFN- $\gamma$ in combination via the JAK/STAT signaling pathway (Lowenstein and Padalko, 2004), we measured the inflammatory response after treatment with LPS and IFN- $\gamma$ combined. However, similar levels of induction of proinflammatory genes was observed in WT and $\mathrm{Atf} 6 \alpha^{-/-}$ microglia (Fig. S 4B).

Atf6 $\alpha$ deficiency promotes degradation of $N F-\kappa B$ p65 in microglia

As previous reports demonstrated a central role of the proteasome in degradation of p65 (Natoli and Chiocca, 2008; Ono et al., 2015), we hypothesized that Atf6 $\alpha$ deficiency might promote proteasome-dependent p65 degradation. In fact, treatment of cells with a proteasome inhibitor MG132 restored the level of p65 in $A t f 6 \alpha^{-/-}$microglia to the similar level observed in WT cells (Fig. 6). Collectively, these results suggest that ATF6 $\alpha$ may regulate the NF-кB-mediated inflammatory response in microglia by controlling p65 degradation. 


\section{Discussion}

In the current study, we first demonstrated that the ATF6 $\alpha$ pathway is activated in the acute phase of EAE. Analysis with WT and Atf6 $\alpha^{-/-}$mice revealed that deletion of Atf $6 \alpha$ suppressed the inflammatory response in microglia/macrophages, and ameliorated demyelination and clinical symptoms. BMT experiments and passive EAE revealed that CNS-resident cells are responsible for the phenotypes observed in Atf $6 \alpha^{-/-}$mice. Furthermore, experiments with cultured cells revealed that deletion of Atf6 $\alpha$ promoted p65 degradation in the NF- $\kappa$ B signaling pathway in microglia. These results indicate that ATF $6 \alpha$ contributes to microglial activation and EAE pathology.

Microglia are CNS-resident macrophages, whose origins were recently identified as the hematopoietic cells of the yolk sac (Prinz et al, 2014). Besides their physiological roles in the CNS, they exert pathological functions upon activation (Prinz et al, 2014). In the field of MS/EAE, both detrimental and beneficial roles for microglia have been reported, but the consensus is that microglia play a pivotal role in MS/EAE pathogenesis, either directly or indirectly through the recruitment of other types of cells including the myelin-reactive $\mathrm{CD} 4^{+} \mathrm{T}$ cells (Xiao et al., 2013; Friese et al., 2014; Duffy et al, 2014). Microglia are discriminated from monocyte-derived macrophages at least by two methods: separation of CD45 ${ }^{\text {hi }}$ and CD $45^{\text {lo }}$ cells by flow cytometry, and development of BM chimera using GFP transgenic mice (Duffy et al., 2014). Therefore, we employed both methods in this study. Expression of NOS2 (iNOS), a marker of inflammation, was reduced in $A t f 6 \alpha^{-/-}$mice-derived $\mathrm{CD} 11 \mathrm{~b}^{+} \mathrm{CD} 45^{\mathrm{lo}}$ cells, but not in $\mathrm{CD} 11 \mathrm{~b}^{+} \mathrm{CD} 45^{\text {hi }}$ cells by flow cytometry after EAE induction (Fig. 3B). Similarly, transfer of $\mathrm{GFP}^{+}$WT BM cells to Atf $6 \alpha^{-/-}$mice did not alter the milder phenotype after EAE (Fig. 4A). Experiments using cultured cells also revealed that the inflammatory response in microglia, but not in astrocytes, was reduced in Atf6 $\alpha$-deleted conditions (Fig. 5 A, B, C, D, E). It is still 
possible, however, that small number of infiltrating macrophages were also affected by the deletion of $A t f 6 \alpha$, and contributed to milder phenotypes after EAE.

In the present study, we employed LPS and, in some cases, IL-1 $\beta, \mathrm{TNF} \alpha$ and IFN- $\gamma$, to induce inflammatory response in cultured microglia. Although LPS may not be involved in the microglia-mediated inflammation in MS/EAE, activation of its receptor, toll- like receptor 4 (TLR4) by endogenous ligands such as fibrinogen, HMGB1, and S100A, collectively termed as damage-associated molecular patterns (DAMPs), has been reported to play a critical role in the same conditions (for review, Gambuzza et al., 2011). Furthermore, microbial infections are an environmental trigger for the onset and persistence of MS, as well as the induction of EAE (Xiao et al., 2013)

In our model, NF-kB p65 level in the nucleus was relatively lower in IL-1 $\beta$ - or TNF $\alpha$-treated conditions, compared with that in LPS-treated condition (Fig. 5B, C). This may be explained by the fact that each signaling pathway recruits different adaptor molecules to activate NF- $\kappa \mathrm{B}$, and, therefore, efficiency may be varied, as previously described (Verstrepen et al., 2008). Regarding IFN- $\gamma$, a key cytokine in EAE released from $\mathrm{T}_{\mathrm{H}} 1$ cells (Rodgers and Miller, 2012), deletion of Atf6 $\alpha$ did not affect its inflammatory response in cultured microglia (Fig. S4 B). The detailed mechanism underlying reduced NF-kB signaling, but not IFN- $\gamma$ signaling, in Atf6 $\alpha^{-/-}$microglia remains to be resolved, but it may include enhancement of NF-אB p65 degradation through the proteasome (Fig. 6). It is noteworthy that other UPR branches, such as PERK and Ire $1 \alpha$, were also reported to activate NF- $\kappa$ B signaling through the translational suppression of IאB $\alpha$ (Deng, et al., 2004; Lin et al., 2013) and the recruitment of IKK (Hu et al., 2006), respectively. We propose a scenario wherein each branch of the UPR regulates NF- $\kappa \mathrm{B}$ signaling by different mechanisms. One of our future studies will therefore be to clarify the relationship between ATF6 $\alpha$ and the E3 ligases involved in p65 degradation (Natoli and Chiocca, 2008; Ono et al., 2015). Although we have not yet clarified why Atf6 $\alpha$ 
deficiency specifically affect microglia during the acute inflammatory stage, we speculate that microglia may have a strong demand for UPR at this time to rapidly produce many secreting and membrane proteins.

In the present study, infiltration of both $\mathrm{CD}^{+}$and $\mathrm{CD} 8^{+}$cells, including the pathological $\mathrm{T}_{\mathrm{H}} 1$ cells, was also suppressed in Atf $6 \alpha^{-/-}$mice (Fig. 2D, E, F). However, the population of T cell-subtypes in peripheral tissues such as the spleen and draining lymph nodes was not altered between the two genotypes after EAE (Fig. S2 A). The recall response of cultured splenocytes and lymphocytes to $\mathrm{MOG}_{35-55}$ peptide was not changed between the two genotypes, either (Fig. S2 C). Finally, adoptive transfer of myelin-reactive CD4 ${ }^{+} \mathrm{T}$ cells, derived from both genotypes, to WT mice caused comparable phenotypes (Fig. 4 C, D). These results suggest that immunoreaction in T cells is not the direct target of ATF6 $\alpha$.

Previous studies have emphasized important roles of PERK signaling in oligodendrocyte survival and remyelination in MS/EAE (Lin and Popko, 2009; Stone and Lin, 2015). It was also recently reported that deletion of GRP78 in oligodendrocytes caused severe impairment in myelination both in physiological and pathological conditions (Hussien et al., 2015). A recent paper further reported that significant upregulation of ATF6 during developmental myelination (Naughton et el., 2015). These observations are in contrast with our finding that ATF6 $\alpha$ plays a role in the inflammatory response in microglia, and contributes to the pathology of EAE. The reason for this discrepancy is currently unknown, but ATF6 $\alpha$ may have both beneficial and detrimental effects, depending on the cell types and timing during the pathophysiology in the CNS. To clarify this point, other demyelination models without severe immunoreaction and/or other animal models such as oligodendrocyte-specific Atf6 $\alpha$ knockout mice need to be employed. It is also intriguing to study the role of PERK signaling or other UPR branches such as ATF6 $\beta$, Ire $1 \alpha$, and Ire $1 \beta$ in microglia-mediated inflammation. 
Our previous studies also indicated that deletion of Atf6 $\alpha$ led to suppression of astroglial activation and glial scar formation, which were associated with enhanced neuronal death in a mouse model of Parkinson's disease (Hashida et al. 2012) and stroke (Yoshikawa et al. 2015). In this study, however, the effect of Atf6 $\alpha$ deficiency was not clear in astrocytes (Fig. S3 A, B), while enhanced level of KDEL expression was observed in the white matter astrocytes after EAE (Fig. 1D). This discrepancy also suggest the limitation of studies using systemic knockout mice, but, again, the role of ATF6 $\alpha$ may have a different impact, depending on the cell types involved and on the pathological conditions. During the course of EAE, inflammation occurs robustly in the CNS from early stage (Fig. 1), while glial scar formation was not clearly observed (Fig. S3 A). In contrast, in Parkinson's disease or stroke model, inflammation may occur in more restricted areas such as substantia nigra and caudate putamen, or ischemic core region

In conclusion, we have demonstrated the pathological role of ATF6 $\alpha$ in EAE, which is associated with microglial-mediated inflammation through the NF- $\mathrm{BB}$ signaling pathway. ATF6 $\alpha$ could be a novel target for regulating inflammatory response in microglia. 


\section{Acknowledgements and conflict of interest disclosure}

We thank Mr. Takashi Tamatani for providing technical assistance. We are also grateful to Dr. Masahito Ikawa (Osaka University) for providing GFP transgenic mice, and Drs. Rieko Muramatsu, Shogo Tanabe, and Toshihide Yamashita (Osaka University) for valuable suggestions regarding EAE. This work was supported by a Grant-in Aid for Scientific Research (24500419 for YK, 26430069 for OH, and 15H01374 for MT) from the Ministry of Education, Science, Technology, Sports and Culture of Japan. The authors declare no conflicts of interest. 


\section{References}

Compston A, Coles A. 2008. Multiple sclerosis. Lancet. 372(9648):1502-17. doi: $10.1016 / \mathrm{S} 0140-6736(08) 61620-7$.

Davalos D, Ryu JK, Merlini M, Baeten KM, Le Moan N, Petersen MA, Deerinck TJ, Smirnoff DS, Bedard C, Hakozaki H, Gonias Murray S, Ling JB, Lassmann H, Degen JL, Ellisman MH, Akassoglou K. 2012. Fibrinogen-induced perivascular microglial clustering is required for the development of axonal damage in neuroinflammation. Nat Commun; 3:1227. doi: $10.1038 /$ ncomms 2230.

Dendrou CA, Fugger L, Friese MA. 2015. Immunopathology of multiple sclerosis. Na Rev Immunol. 15(9):545-58. doi: 10.1038/nri3871.

Deng J, Lu PD, Zhang Y, Scheuner D, Kaufman RJ, Sonenberg N, Harding HP, Ron D. 2004. Translational repression mediates activation of nuclear factor kappa B by phosphorylated translation initiation factor 2. Mol Cell Biol. 24(23):10161-8.

Duffy SS, Lees JG, Moalem-Taylor G. 2014. The contribution of immune and glial cell types in experimental autoimmune encephalomyelitis and multiple sclerosis. Mult Scler Int. 2014:285245. doi: 10.1155/2014/285245. doi: 10.1155/2014/285245.

Friese MA, Schattling B, Fugger L. 2014. Mechanisms of neurodegeneration and axonal dysfunction in multiple sclerosis. Nat Rev Neurol. 10(4):225-38. doi: 10.1038/nrneurol.2014.37.

Gambuzza M, Licata N, Palella E, Celi D, Foti Cuzzola V, Italiano D, Marino S, Bramanti P. 2011. Targeting Toll-like receptors: emerging therapeutics for multiple sclerosis management. J Neuroimmunol. 239(1-2):1-12. doi: 10.1016/j.jneuroim.2011.08.010

Giulian D, Baker TJ. 1985. Peptides released by ameboid microglia regulate astroglial proliferation. J Cell Biol. 101(6):2411-5. 
Goldmann T, Wieghofer P, Müller PF, Wolf Y, Varol D, Yona S, Brendecke SM, Kierdorf K, Staszewski O, Datta M, Luedde T, Heikenwalder M, Jung S, Prinz M. 2013. A new type of microglia gene targeting shows TAK1 to be pivotal in CNS autoimmune inflammation. Nat Neurosci. 2013 Nov;16(11):1618-26. doi: 10.1038/nn.3531.

Hashida K, Kitao Y, Sudo H, Awa Y, Maeda S, Mori K, Takahashi R, Iinuma M, Hori O. 2012. ATF6alpha promotes astroglial activation and neuronal survival in a chronic mouse model of Parkinson's disease. PLoS One. 7(10):e47950. doi: 10.1371/journal.pone.0047950.

Hickey WF, Vass K, Lassmann H. 1992. Bone marrow-derived elements in the central nervous system: an immunohistochemical and ultrastructural survey of rat chimeras. J Neuropathol Exp Neurol. 51(3):246-56.

Hu P, Han Z, Couvillon AD, Kaufman RJ, Exton JH. 2006. Autocrine tumor necrosis factor alpha links endoplasmic reticulum stress to the membrane death receptor pathway through IRE1 alpha-mediated NF-kappaB activation and down-regulation of TRAF2 expression. Mol Cell Biol. 26(8):3071-84.

Hussien Y, Cavener DR, Popko B. 2014. Genetic inactivation of PERK signaling in mouse oligodendrocytes: normal developmental myelination with increased susceptibility to inflammatory demyelination. Glia. 62(5):680-91. doi: 10.1002/glia.22634.

Hussien Y, Podojil JR, Robinson AP, Lee AS, Miller SD, Popko B. 2015. ER Chaperone BiP/GRP78 Is Required for Myelinating Cell Survival and Provides Protection during Experimental Autoimmune Encephalomyelitis. J Neurosci.;35(48):15921-33. doi: 10.1523/JNEUROSCI.0693-15.2015.

Kezuka D, Takarada-Iemata M, Hattori T, Mori K, Takahashi R, Kitao Y, Hori O. 2015. Deletion of Atf6 $\alpha$ enhances kainate-induced neuronal death in mice. Neurochem Int. pii: S0197-0186(15)30078-4. doi: 10.1016/j.neuint.2015.12.009. 
Kitamura M. 2011. Control of NF- $\mathrm{BB}$ and inflammation by the unfolded protein response. Int Rev Immunol. 30(1):4-15. doi: 10.3109/08830185.2010.522281.

Lin W, Kemper A, Dupree JL, Harding HP, Ron D, Popko B. 2006. Interferon-gamma inhibits central nervous system remyelination through a process modulated by endoplasmic reticulum stress. Brain. 129(Pt 5):1306-18.

Lin W, Bailey SL, Ho H, Harding HP, Ron D, Miller SD, Popko B. 2007. The integrated stress response prevents demyelination by protecting oligodendrocytes against immune-mediated damage. J Clin Invest. 117(2):448-56.

Lin W, Popko B. 2009. Endoplasmic reticulum stress in disorders of myelinating cells. Nat Neurosci. 12(4):379-85. doi: 10.1038/nn.2273.

Lin W, Lin Y, Li J, Fenstermaker AG, Way SW, Clayton B, Jamison S, Harding HP, Ron D, Popko B. 2013. Oligodendrocyte-specific activation of PERK signaling protects mice against experimental autoimmune encephalomyelitis. J Neurosci. 33(14):5980-91. doi:10.1523/JNEUROSCI.1636-12.2013.

Lin Y, Huang G, Jamison S, Li J, Harding HP, Ron D, Lin W. 2014. PERK activation preserves the viability and function of remyelinating oligodendrocytes in immune-mediated demyelinating diseases. Am J Pathol. 184(2):507-19. doi: 10.1016/j.ajpath.2013.10.009.

Lowenstein CJ, Padalko E. 2004. iNOS (NOS2) at a glance. J Cell Sci. 117(Pt 14):2865-7. McCarthy KD, de Vellis J. 1980. Preparation of separate astroglial and oligodendroglial cell cultures from rat cerebral tissue. J Cell Biol. 85(3):890-902

McCloy RA, Rogers S, Caldon CE, Lorca T, Castro A, Burgess A. 2014. Partial inhibition of Cdk1 in G 2 phase overrides the SAC and decouples mitotic events. Cell Cycle 13, 1400-1412

Mháille AN, McQuaid S, Windebank A, Cunnea P, McMahon J, Samali A, FitzGerald U. 2008. Increased expression of endoplasmic reticulum stress-related signaling pathway molecules 
in multiple sclerosis lesions. J Neuropathol Exp Neurol. 67(3):200-11. doi:

10.1097/NEN.0b013e318165b239.

Miller SD, Karpus WJ, Davidson TS. 2010. Experimental autoimmune encephalomyelitis in the mouse. Curr Protoc Immunol. Chapter 15:Unit 15.1. doi:

10.1002/0471142735.im1501s88.

Mori K. 2009. Signalling pathways in the unfolded protein response: development from yeast to mammals. J Biochem. 146(6):743-50. doi: 10.1093/jb/mvp166. Epub 2009 Oct 27.

Muramatsu R, Kubo T, Mori M, Nakamura Y, Fujita Y, Akutsu T, Okuno T, Taniguchi J, Kumanogoh A, Yoshida M, Mochizuki H, Kuwabara S, Yamashita T. 2011. RGMa modulates T cell responses and is involved in autoimmune encephalomyelitis. Nat Med. 17(4):488-94. doi: $10.1038 / \mathrm{nm} .2321$.

Natoli G, Chiocca S. 2008. Nuclear ubiquitin ligases, NF-kappaB degradation, and the control of inflammation. Sci Signal. 1(1):pe1. doi: 10.1126/stke.11pe1.

Naughton MC, McMahon JM, FitzGerald U. 2015. Differential activation of ER stress pathways in myelinating cerebellar tracts. Int J Dev Neurosci. 47(Pt B):347-60. doi: 10.1016/j.ijdevneu.2015.08.002.

Ní Fhlathartaigh M1, McMahon J, Reynolds R, Connolly D, Higgins E, Counihan T, Fitzgerald U. 2013. Calreticulin and other components of endoplasmic reticulum stress in rat and human inflammatory demyelination. Acta Neuropathol Commun. 1:37. doi: $10.1186 / 2051-5960-1-37$.

Okabe M1, Ikawa M, Kominami K, Nakanishi T, Nishimune Y. 1997. 'Green mice' as a source of ubiquitous green cells. FEBS Lett. 407(3):313-9.

Ono R, Kaisho T, Tanaka T. 2015. PDLIM1 inhibits NF-кB-mediated inflammatory signaling

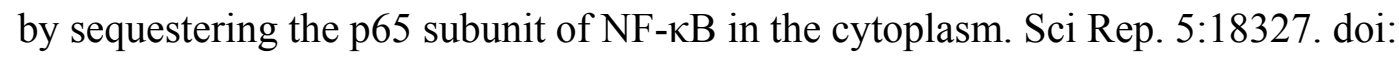
$10.1038 /$ srep 18327. 
Prinz M1, Tay TL, Wolf Y, Jung S. 2014. Microglia: unique and common features with other tissue macrophages. Acta Neuropathol. 128(3):319-31. doi: 10.1007/s00401-014-1267-1. Epub 2014 Mar 21.

Renard P, Ernest I, Houbion A, Art M, Le Calvez H, Raes M, Remacle J. 2001. Development of a sensitive multi-well colorimetric assay for active NFkappaB. Nucleic Acids Res. 2001 Feb 15;29(4):E21.

Rodgers JM, Miller SD. 2012, Cytokine control of inflammation and repair in the pathology of multiple sclerosis. Yale J Biol Med. 85(4):447-68. Epub 2012 Dec 13.

Schattling B, Steinbach K, Thies E, Kruse M, Menigoz A, Ufer F, Flockerzi V, Brück W, Pongs O, Vennekens R, Kneussel M, Freichel M, Merkler D, Friese MA. 2012. TRPM4 cation channel mediates axonal and neuronal degeneration in experimental autoimmune encephalomyelitis and multiple sclerosis. Nat Med. 18(12):1805-11. doi: 10.1038/nm.3015.

Southwood CM, Garbern J, Jiang W, Gow A. 2002. The unfolded protein response modulates disease severity in Pelizaeus-Merzbacher disease. Neuron. 36(4):585-96.

Stone S, Lin W. 2015. The unfolded protein response in multiple sclerosis. Front Neurosci. 9:264. doi: 10.3389/fnins.2015.00264.

Stromnes IM, Goverman JM. 2006A. Active induction of experimental allergic encephalomyelitis. Nat Protoc. 1(4):1810-9.

Stromnes IM, Goverman JM. 2006B. Passive induction of experimental allergic encephalomyelitis. Nat Protoc. 1(4):1952-60.

Takano K, Tabata Y, Kitao Y, Murakami R, Suzuki H, Yamada M, Iinuma M, Yoneda Y, Ogawa S, Hori O. 2007. Methoxyflavones protect cells against endoplasmic reticulum stress and neurotoxin. Am J Physiol Cell Physiol. 292(1):C353-61. 
Verstrepen L, Bekaert T, Chau TL, Tavernier J, Chariot A, Beyaert R. 2008. TLR-4, IL-1R and TNF-R signaling to NF-kappaB: variations on a common theme. Cell Mol Life Sci. 65(19):2964-78. doi: 10.1007/s00018-008-8064-8.

Walter P, Ron D. 2011. The unfolded protein response: from stress pathway to homeostatic regulation. Science. 334(6059):1081-6. doi: 10.1126/science.1209038.

Xiao Y, Jin J, Chang M, Chang JH, Hu H, Zhou X, Brittain GC, Stansberg C, Torkildsen Ø, Wang X, Brink R, Cheng X, Sun SC. 2013. Pelil promotes microglia-mediated CNS inflammation by regulating Traf3 degradation. Nat Med. 19(5):595-602. doi: 10.1038/nm.3111.

Yamamoto K., Sato T., Matsui T. et al. 2007. Transcriptional induction of mammalian ER quality control proteins is mediated by single or combined action of ATF6alpha and XBP1. Dev Cell. 13, 365-376.

Yoshikawa A, Kamide T, Hashida K, Ta HM, Inahata Y, Takarada-Iemata M, Hattori T, Mori K, Takahashi R, Matsuyama T, Hayashi Y, Kitao Y, Hori O. 2015. Deletion of Atf6 $\alpha$ impairs astroglial activation and enhances neuronal death following brain ischemia in mice. J Neurochem. 132(3):342-53. doi: 10.1111/jnc.12981.

Zhang K, Kaufman RJ. 2008. From endoplasmic-reticulum stress to the inflammatory response. Nature. 454(7203):455-62. doi: 10.1038/nature07203. 


\section{Figure Legends}

Figure 1. Expression of UPR-target genes during the course of EAE. A, B, EAE was induced in WT (C57BL/6) mice, and total RNA (A) or proteins (B) were extracted from the lumbar part of the spinal cord, and subjected to qRT-PCR and western blot, respectively. In A, typical results of qRT-PCR using RNA samples (4-8 mice per group) from three independent experiments are shown. The values are mean \pm s.e.m. $* * \mathrm{P}<0.01, * * * \mathrm{P}<0.001$ compared to control, one-way ANOVA followed by Tukey test. In B, typical results of western blot using protein samples (3-4 mice per group) from three independent experiments are shown. The values are mean \pm s.e.m. $* * \mathrm{P}<0.01, * * * \mathrm{P}<0.001$ compared to control, Student's t-test. $\mathrm{C}, \mathrm{D}$, Spinal cord sections, either from control mice or from EAE mice, were subjected to immunohistochemistry with indicated antibodies. Scale bars: $200 \mu \mathrm{m}(\mathrm{C}), 15 \mu \mathrm{m}$ (D). The typical results of 6 mice from four independent experiments are shown. GM: gray matter, WM: white matter. Arrowheads and arrow indicate high and low level of expression of KDEL in oligodendrocytes.

Figure 2. Reduced severity in $\mathbf{A t f b}^{-/-}$mice after induction of EAE. A, Mean clinical scores in WT and Atf $6 \alpha^{-/-}$mice after induction of EAE. Twelve WT mice and 13 Atf6 $\alpha^{-/-}$mice from three independent experiments (4-5 mice/group) were analyzed. The values are mean \pm s.e.m. $* * * \mathrm{P}<0.0001$ between two genotypes, two-way ANOVA. B, C, H\&E staining (B) and immunohistochemistry $(\mathrm{C})$ of the spinal cord at the acute phase of EAE. Note that, the invasion of inflammatory cells and demyelination were reduced in $A t f 6 \alpha^{-/-}$mice at the acute phase of EAE. Scale bars: $50 \mu \mathrm{m}$. Two slices per mouse and four mice per genotype from three independent experiments were analyzed. The values are mean \pm s.e.m. $* \mathrm{P}<0.05$ between two genotypes, Student's t-test. D, E, F, Flow cytometry analysis of immune cell infiltrates in the 
CNS of WT and $\mathrm{Atf} 6 \alpha^{-/-}$mice at the acute phase of EAE. Seven mice per genotype from four independent experiments (D) and 5 mice per genotype from three independent experiments (E, F) were analyzed. The numbers in the plots indicate the percentages of each gated cell population among the total CNS-infiltrating cells (D). Both of the percentage and the absolute number of the CNS-infiltrating cells (D) and IFN- $\gamma^{+}$or IL- $17^{+} \mathrm{CD} 4^{+} \mathrm{T}$ cells $(\mathrm{E}, \mathrm{F})$ in the CNS of both genotypes are shown. The values shown are the mean \pm s.e.m. $* \mathrm{P}<0.05, * * \mathrm{P}<0.01$ between two genotypes, Student's t-test.

Figure 3. Impaired microglia/macrophage activation in $A t f 6 \alpha^{-/-}$mice after induction of

EAE. A, Immunohistochemistry of the spinal cord in the control and at the acute phase of EAE. Spinal cord sections from WT and $A t f 6 \alpha^{-/-}$mice both under control and EAE conditions were prepared, and subjected to immunohistochemistry for Iba1. Scale bars: $200 \mu \mathrm{m}$ at low magnification and $25 \mu \mathrm{m}$ at high magnification. Two slices per mouse and six mice per genotype from three independent experiments were analyzed. The values shown are the mean \pm s.e.m. ${ }^{* * *} \mathrm{P}<0.001$ between two genotypes, Student's t-test. B, Flow cytometry analysis of microglia and macrophages in the CNS from WT and $A t f 6 \alpha^{-/-}$mice at the acute phase of EAE. The percentage of $\mathrm{NOS}_{2}{ }^{+}$cells are shown. Three mice per genotype from three independent experiments were analyzed. The values shown are the mean \pm s.e.m. $* \mathrm{P}<0.05$ between two genotypes, Student's t-test. C, Immunohistochemical analysis of NF- $\mathrm{B}$ p65 in white matter of the spinal cord after EAE. The spinal cord from WT and Atf $6 \alpha^{-/-}$mice at the acute phase of EAE was subjected to immunohistochemistry for p65 and Iba1. Note that the ratio of NF-kB p $65^{+} \mathrm{Iba}^{+}$cells versus Iba $1^{+}$cells was much lower in $A t f 6 \alpha^{-/-}$microglia. Scale bars: $50 \mu \mathrm{m}$ Two slices per mouse and six mice per genotype from three independent experiments were analyzed. Values shown are the mean \pm s.e.m. $* \mathrm{P}<0.05, * * \mathrm{P}<0.01$ between two genotypes, Student's t-test. 


\section{Figure 4. Bone marrow transfer (BMT) experiments and adoptive transfer of} autoimmune $\mathrm{CD4}^{+} \mathrm{T}$ cells to recipient mice (passive EAE). A, B, BMT. Lethally irradiated WT and $A t f 6 \alpha^{-/-}$mice received BMT from $\mathrm{GFP}^{+} \mathrm{WT}$ mice, and EAE was induced after their recovery. Eight WT mice and $7 \mathrm{Atf6} \alpha^{-/-}$mice were analyzed from two independent experiments. A, Mean clinical scores are indicated as mean value \pm s.e.m. $* \mathrm{P}<0.05$ between two genotypes, two-way ANOVA. B, Spinal cords from WT and Atf6 $\alpha^{-/-}$mice after BMT/EAE were subjected to immunohistochemistry for GFP. Scale bars: $200 \mu \mathrm{m}$. C, D, Passive EAE. Restimulated CD4 $4^{+}$T cells, derived from both WT and Atf6 $\alpha^{-/-}$mice, were transferred to sublethally irradiated WT recipient mice. Four mice per genotype were analyzed from two independent experiments. $\mathrm{C}$, Mean clinical scores are indicated as mean value \pm s.e.m. ${ }^{*} \mathrm{P}<$ 0.05 between two genotypes, two-way ANOVA. D, Spinal cords from WT and Atf6 $\alpha^{-/-}$mice after passive EAE were subjected to H\&E staining. Scale bars: $200 \mu \mathrm{m}$.

\section{Figure 5. Impaired signal transduction of the NF-кB pathway in $A t f 6 \alpha^{-/}$microglia. A,} Western blot analysis of the NF- $\kappa$ B pathway. Whole cell lysates from cultured WT and Atf6 $\alpha^{-/-}$ microglia stimulated with LPS $(100 \mathrm{ng} / \mathrm{ml})$ for the indicated times were subjected to western blot for the indicated molecules. Values shown are the mean \pm s.e.m. from three independent experiments. $* \mathrm{P}<0.05, * * \mathrm{P}<0.01$ between two genotypes, Student's t-test. $\mathrm{B}, \mathrm{C}$,

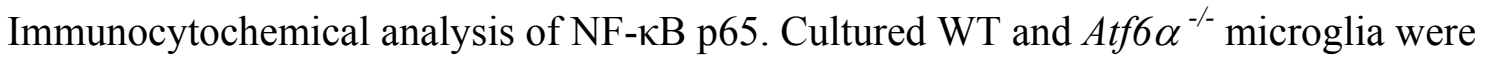
stimulated with LPS (100 ng/ml) for 1h, IL-1 $\beta(100 \mathrm{ng} / \mathrm{ml})$ for $1 \mathrm{~h}$, or TNF $\alpha(20 \mathrm{ng} / \mathrm{ml})$ for 30min, and, after fixation, subjected to immunocytochemistry for p65 and Iba1. Scale bars: $20 \mu \mathrm{m}$. In $\mathrm{C}$, the intensity of p65 in the nucleus was quantified, as described in Materials and Methods. Ninety cells per condition from three independent experiments were analyzed. Values shown are the mean \pm s.e.m. $* * \mathrm{P}<0.001$ between two genotypes, one-way ANOVA 
followed by Tukey test. D, Binding of NF- $\kappa \mathrm{B}$ to its consensus DNA sequence. The binding of $\mathrm{NF}-\kappa \mathrm{B}$ to its consensus DNA sequence was measured as described in the text. Results from four independent experiments are shown. Values are the mean \pm s.e.m. ${ }^{*} \mathrm{P}<0.05$, compared with untreated condition, one-way ANOVA followed by Tukey test. E, Induction of NF- $\mathrm{B}$ downstream genes in cultured WT and Atf6 $\alpha^{-/-}$microglia. Cells were stimulated with LPS (100 $\mathrm{ng} / \mathrm{ml}$ ) the indicated times, and total RNA was subjected to qRT-PCR analysis. The values shown are the mean \pm s.e.m. from three independent experiments. $* * \mathrm{P}<0.01$ between two genotypes, Student's t-test.

Figure 6. Proteasome-dependent degradation of NF-кB p65 in Atf6 $\alpha^{-/-}$microglia. Whole cell lysates from WT and Atf6 $\alpha^{-/-}$microglia stimulated with LPS (100 ng/ml) with/without MG132 $(10 \mu \mathrm{M})$ for $60 \mathrm{~min}$ were subjected to western blot for the indicated molecules. Values shown are the mean \pm s.e.m. from three independent experiments. $* \mathrm{P}<0.05$, $* * \mathrm{P}<0.01$, one-way ANOVA followed by Tukey test. 


\title{
Supplementary information
}

\section{Atf6 $\alpha$ deficiency suppresses microglial activation and ameliorates pathology of experimental autoimmune encephalomyelitis}

\author{
Hieu Minh $\mathrm{Ta}^{1}$, Thuong Manh Le ${ }^{1}$, Hiroshi Ishii ${ }^{1}$, Mika Takarada-Iemata ${ }^{1}$, Tsuyoshi Hattori ${ }^{1}$, \\ Koji Hashida ${ }^{1}$, Yasuhiko Yamamoto ${ }^{2}$, Kazutoshi Mori ${ }^{3}$, Ryosuke Takahashi ${ }^{4}$, Yasuko Kitao ${ }^{1}$, \\ Osamu Hori ${ }^{*}$ \\ ${ }^{1}$ Department of Neuroanatomy, Graduate School of Medical Sciences, Kanazawa University \\ ${ }^{2}$. Department of Biochemistry and Molecular Vascular Biology, Graduate School of Medical \\ Sciences, Kanazawa University \\ ${ }^{3}$ Department of Biophysics, Graduate School of Science, Kyoto University, \\ ${ }^{4}$ Department of Neurology, Graduate School of Medicine, Kyoto University
}

\section{Supplemental Figure Legends}

Figure S1. Expression of GRP78 and GRP94 in the chronic phase of EAE. Proteins samples were extracted from the lumbar part of the spinal cord of WT mice, and subjected to western blot. Typical results (3-4 mice per group) from three independent experiments are shown. The values are mean \pm s.e.m. $* * \mathrm{P}<0.01, * * * \mathrm{P}<0.001$ compared to control, Student's t-test.

Figure S2. Activation status of lymphocytes in WT and Atf6 $\alpha^{-/-}$mice. A, B, Flow cytometric analysis of lymphocytes from peripheral tissues at the acute phase of EAE. Five mice per genotype from three independent experiments were analyzed. The percentage and the absolute number of lymphocyte population (A) and that of IFN- $\gamma^{+} \mathrm{CD} 4^{+}$or IL-17 ${ }^{+} \mathrm{CD} 4^{+} \mathrm{T}$ cells (B) are shown. The values shown are the mean \pm s.e.m. ns, not significant, Student's t-test. C, Recall response of splenocytes and lymphocytes against the $\mathrm{MOG}_{35-55}$ peptide. Isolated splenocytes and lymphocytes were re-stimulated with $\mathrm{MOG}_{35-55}$ for 3 days, and then subjected to BrdU incorporation assay $(\mathrm{C})$. The values shown are the mean \pm s.e.m. one-way ANOVA followed by Tukey test. Three mice per genotypes from three independent experiments were analyzed. 
Figure S3. Activation status of astrocytes in vivo and in vitro. A, Immunohistochemistry of the spinal cord in the control and at the acute phase of EAE. Spinal cord sections from WT and Atf6 $\alpha^{-/-}$mice under both control and acute EAE conditions, subjected to immunohistochemistry for GFAP. Two slices per mouse and four mice per genotype from two independent experiments were analyzed. Scale bars: $200 \mu \mathrm{m}$ at low magnification and $25 \mu \mathrm{m}$ at high magnification. B, WT and Atf6 $\alpha^{-/-}$astrocytes in culture were stimulated with LPS (100 $\mathrm{ng} / \mathrm{ml}$ ), or incubated in the medium alone (untreated) for $16 \mathrm{~h}$, and total RNA was subjected to qRT-PCR analysis for proinflammatory gene expression. Values shown are the mean \pm s.e.m. from three independent experiments.

Figure S4. Signal transduction of the MAPK pathway after LPS treatment and induction of NF-кB downstream genes after IFN $\gamma$ treatment in microglia. A, Whole cell lysates from WT and $A t f 6 \alpha^{-/}$microglia, stimulated with LPS (100 ng/ml) for the indicated times were subjected to western blot for the indicated molecules. Values shown are the mean \pm s.e.m. from three independent experiments. $* \mathrm{P}<0.05$, $* * \mathrm{P}<0.01$, Student's t-test. B, WT and Atf6 $\alpha^{-/-}$ microglia were stimulated with LPS (100 ng/ml) and IFN- $\gamma(20 \mathrm{ng} / \mathrm{ml})$, and total RNA was subjected to qRT-PCR analysis for proinflammatory gene expression. The values shown are the mean \pm s.e.m. from three independent experiments. ns: not significant, Student's t-test.

Figure S5. Immunohistochemistry of the spinal cord at the acute phase of EAE. Different area of the spinal cord from that in Fig. $2 \mathrm{C}$ was shown for both genotypes. Scale bars: $50 \mu \mathrm{m}$. 
A
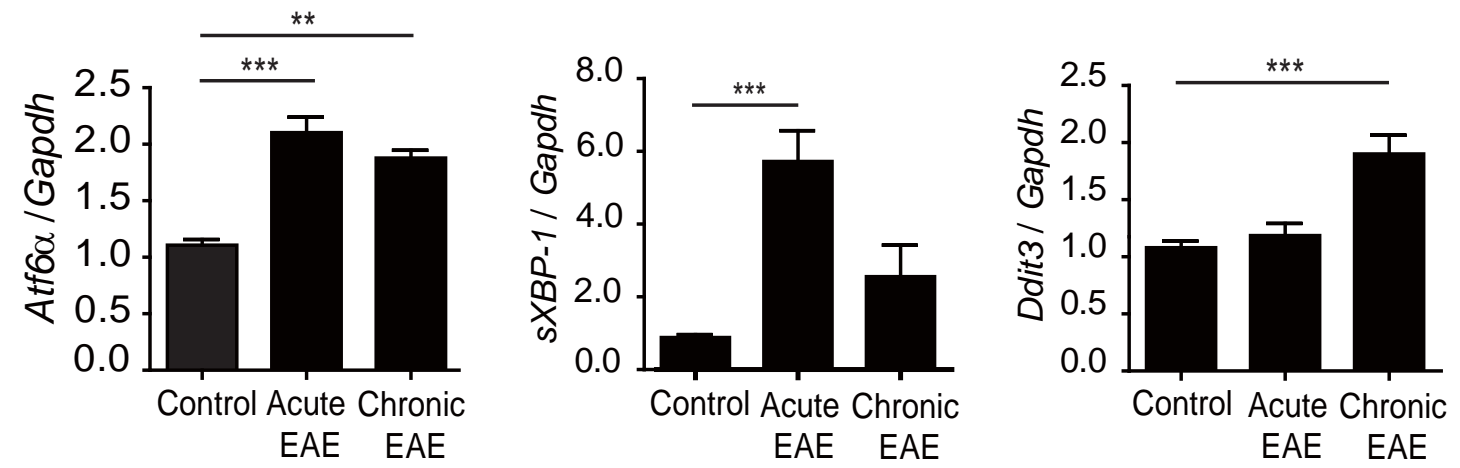

B
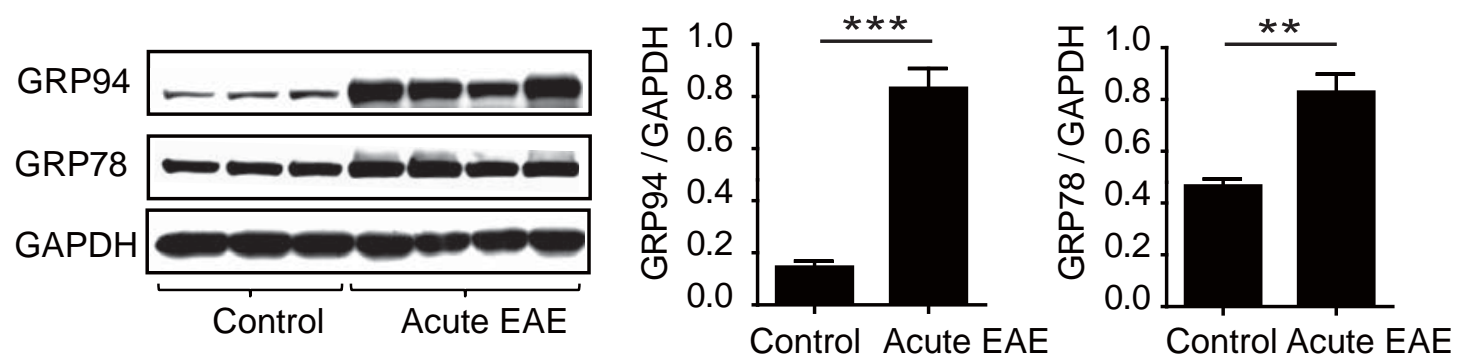

C
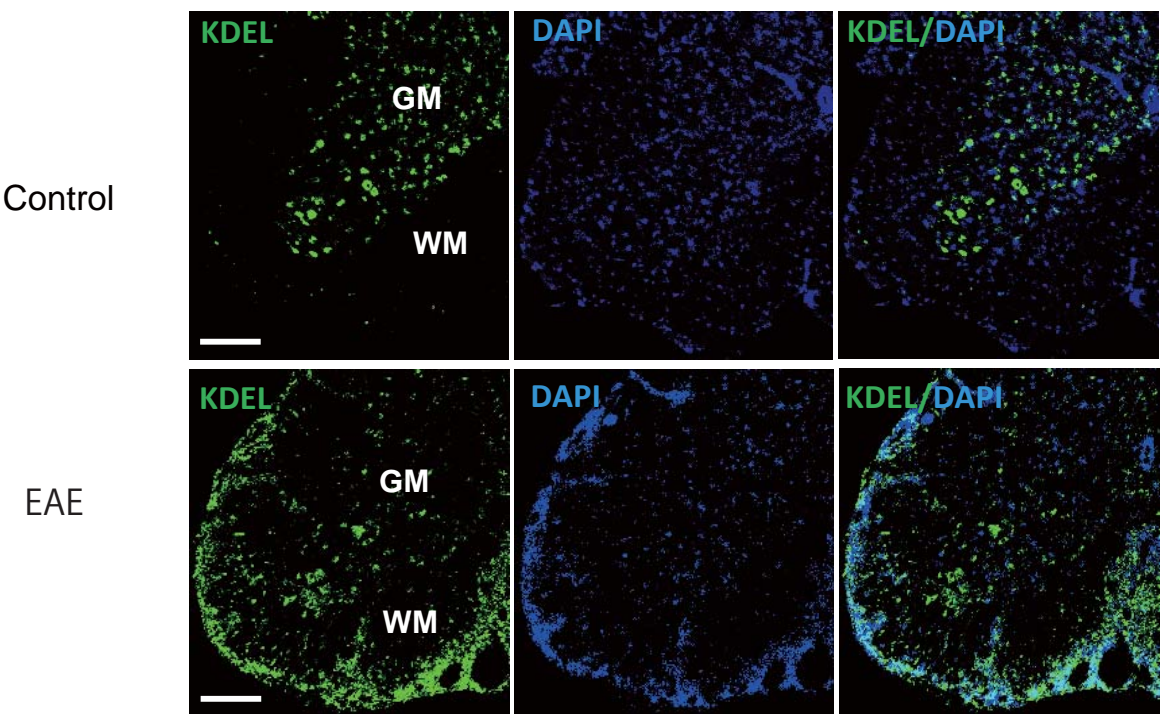

D

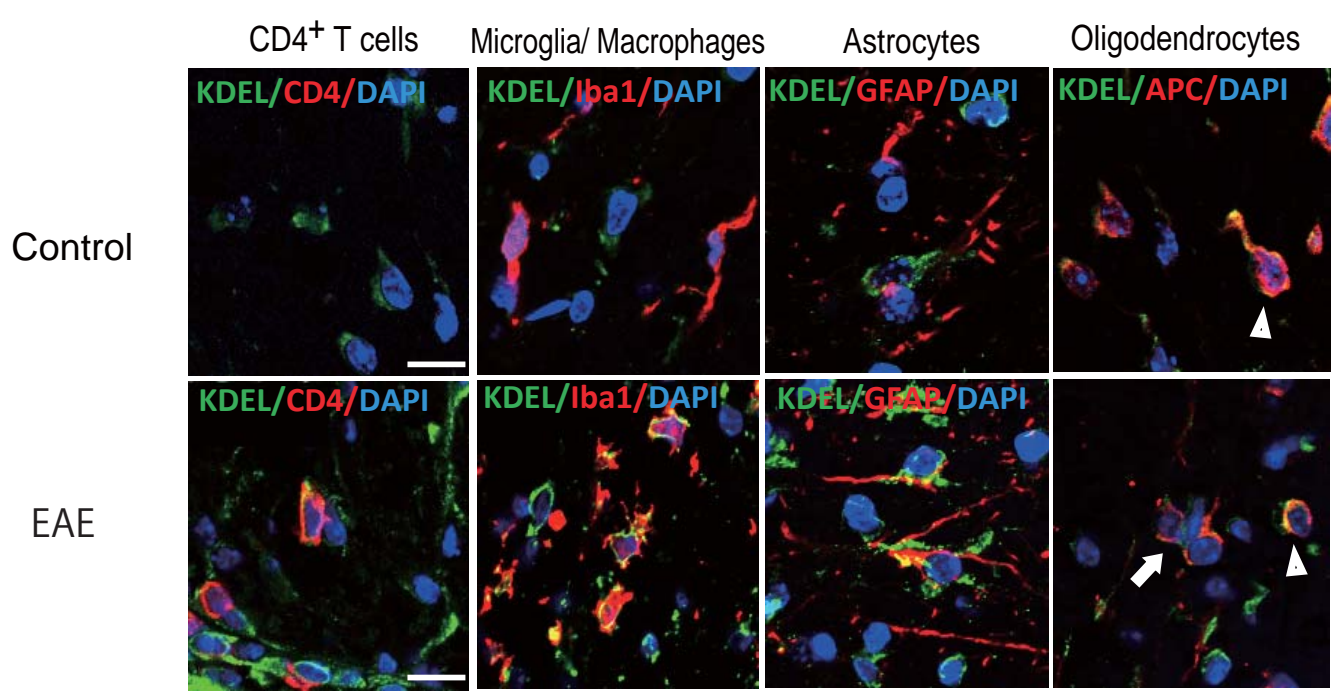

Fig. 1 

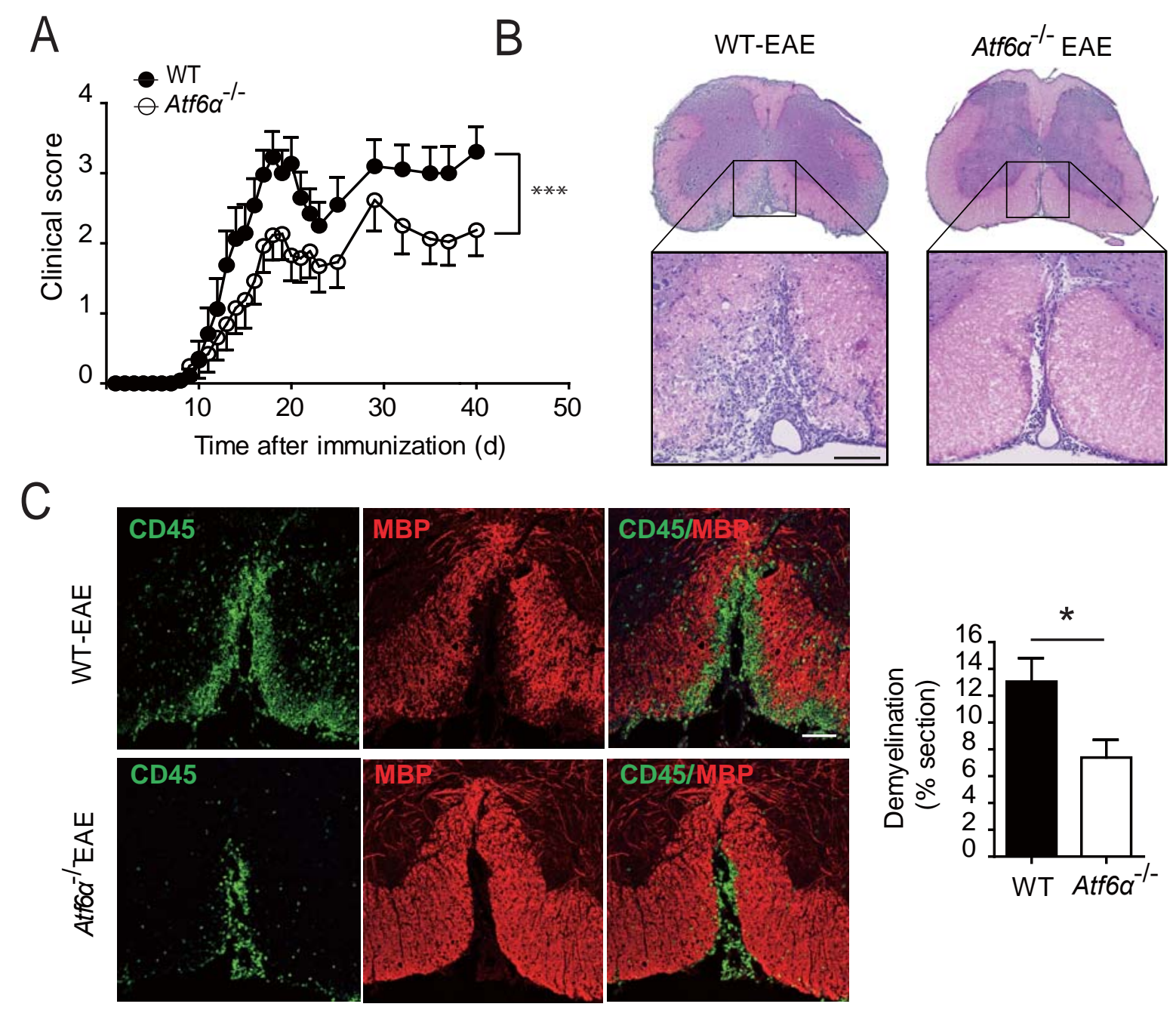

D

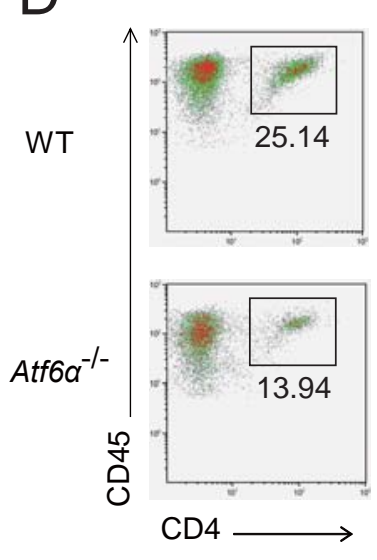

E

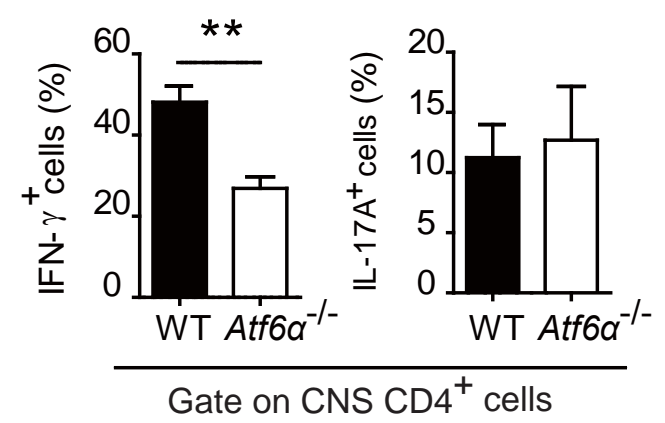

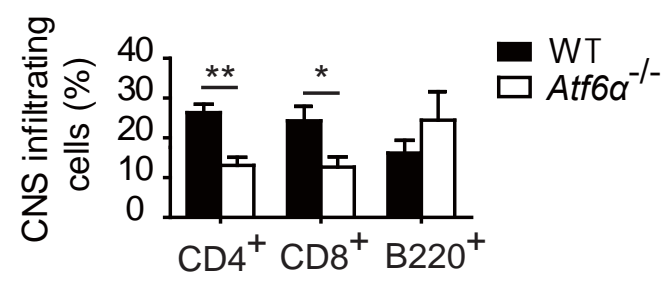

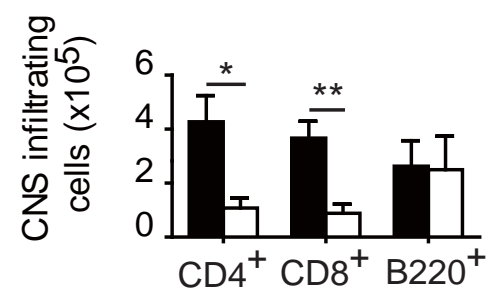

F

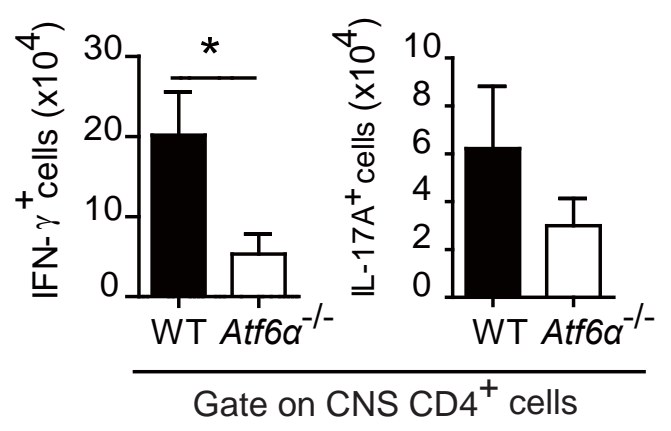

Fig. 2 
A

Control

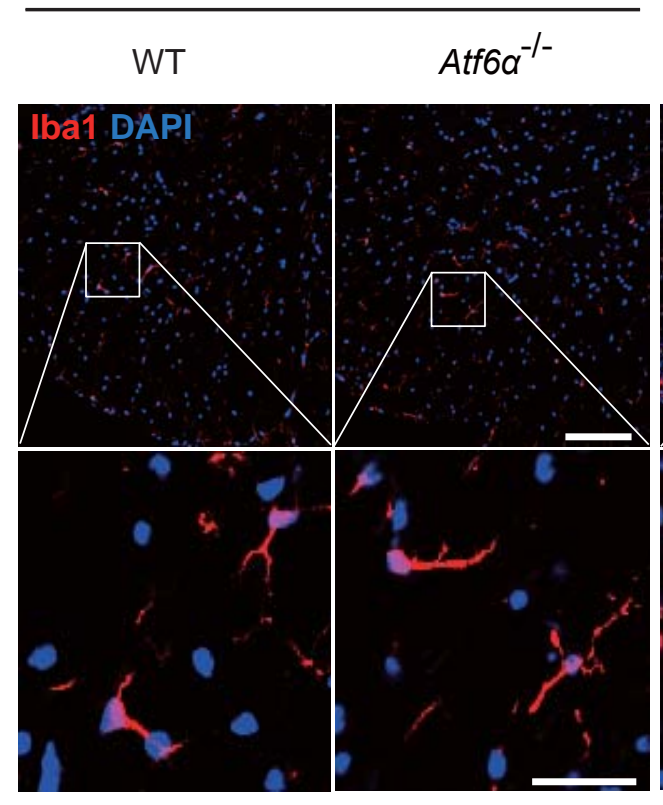

B

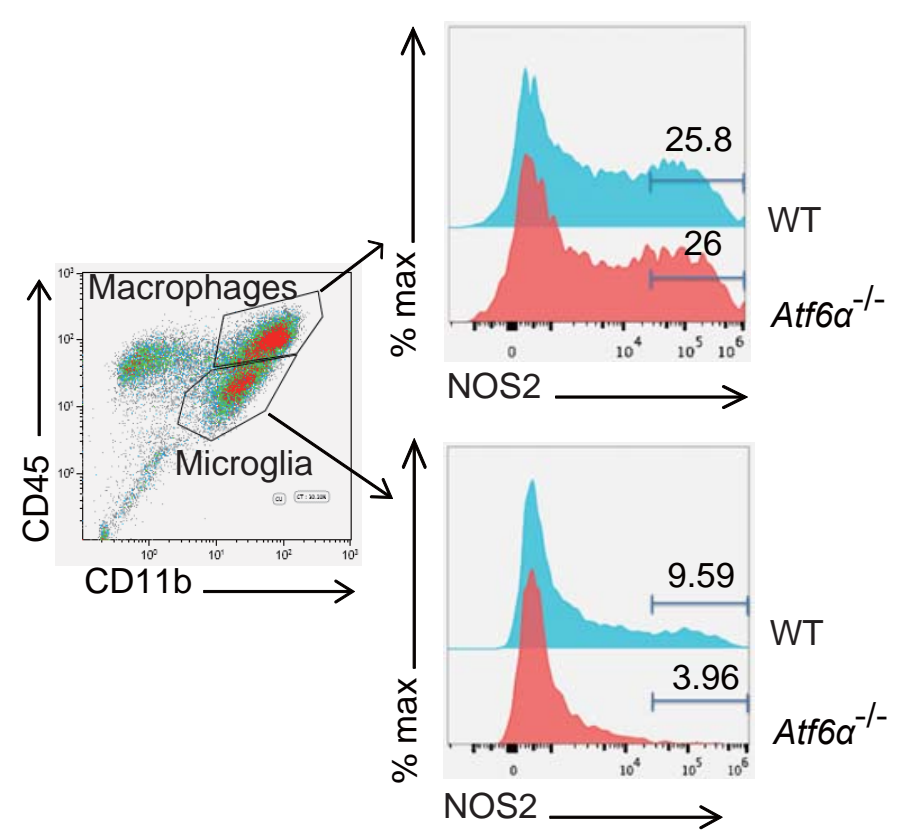

EAE
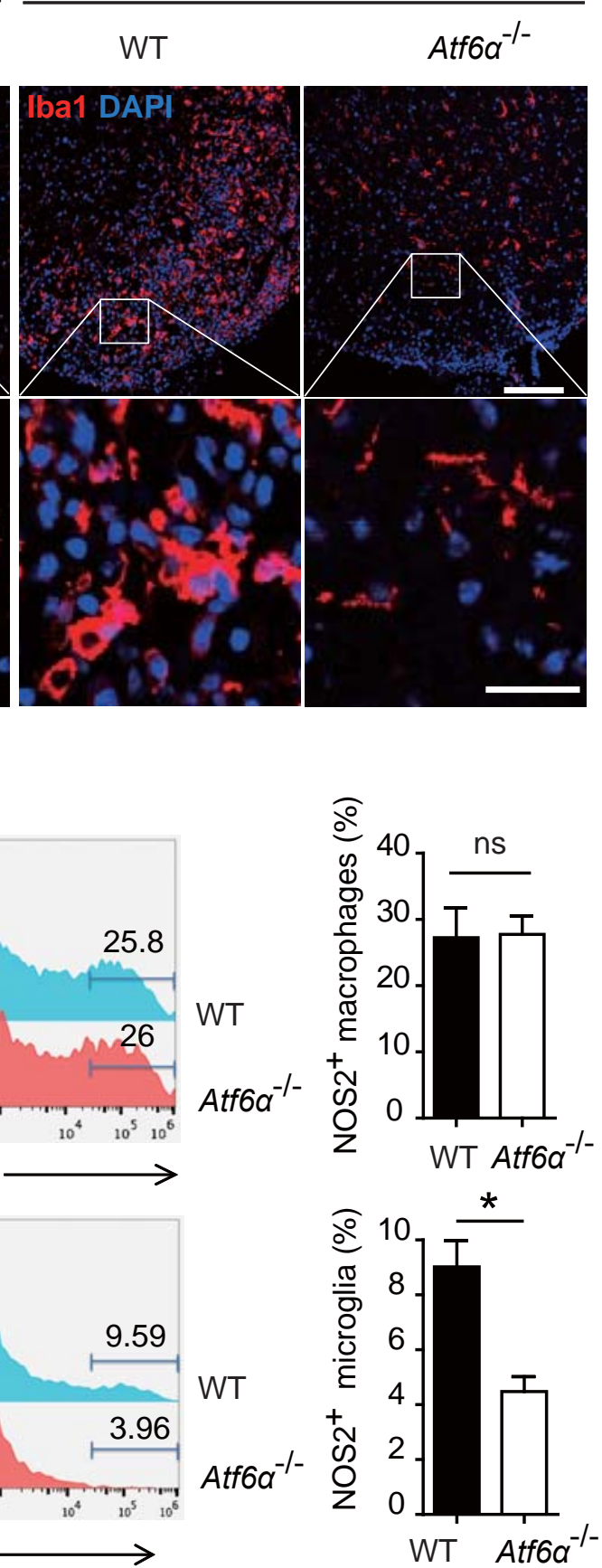

C
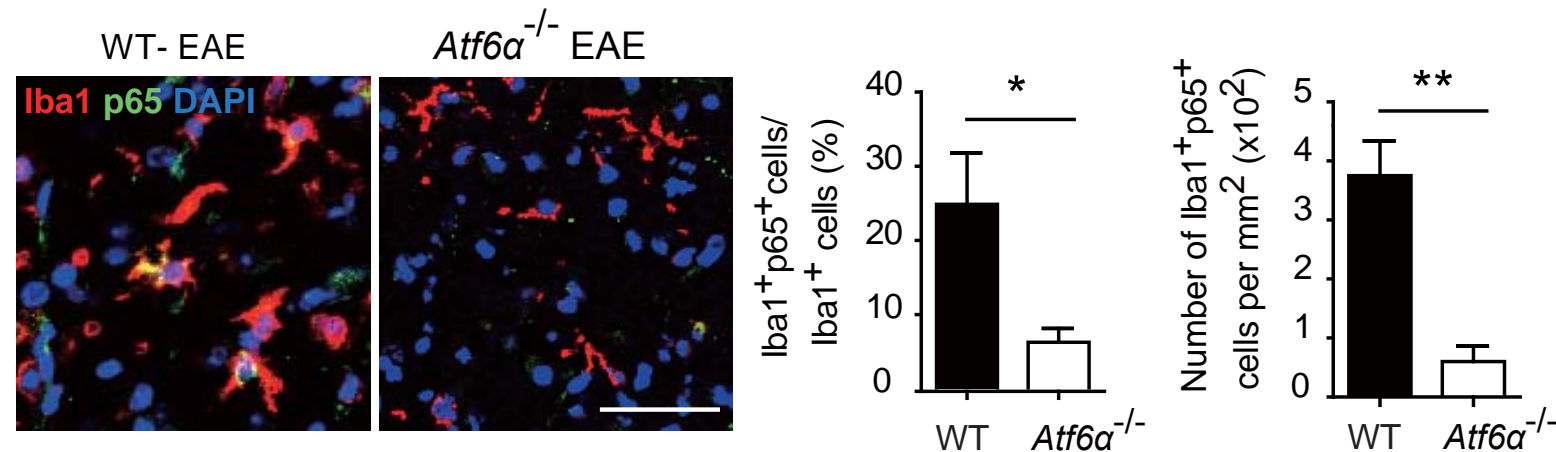

Fig. 3 
A

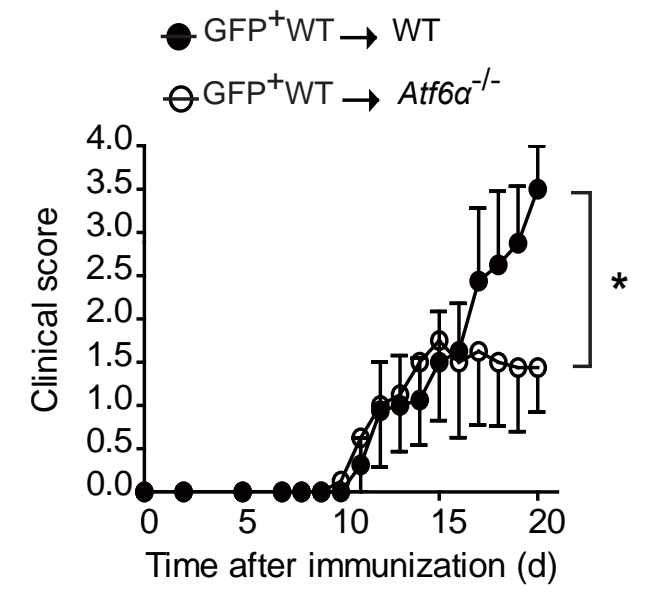

C

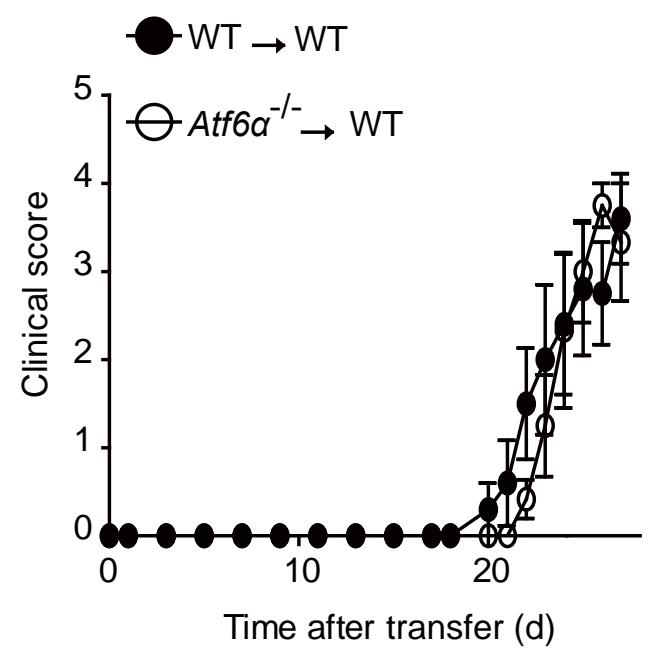

B

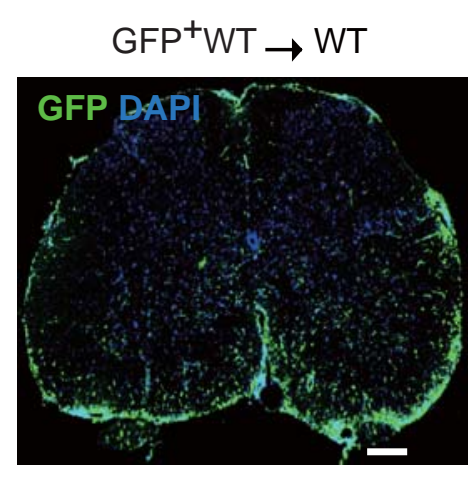

$\mathrm{GFP}^{+} \mathrm{WT} \rightarrow$ Atf6 $\alpha^{-/-}$

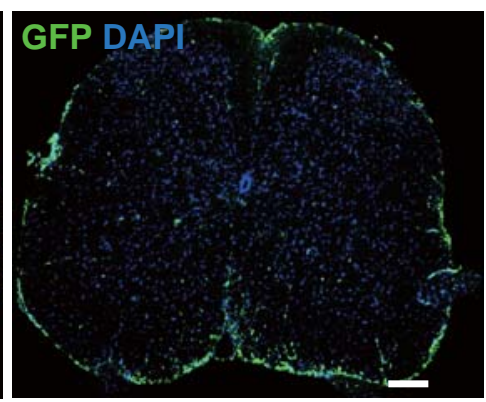

D
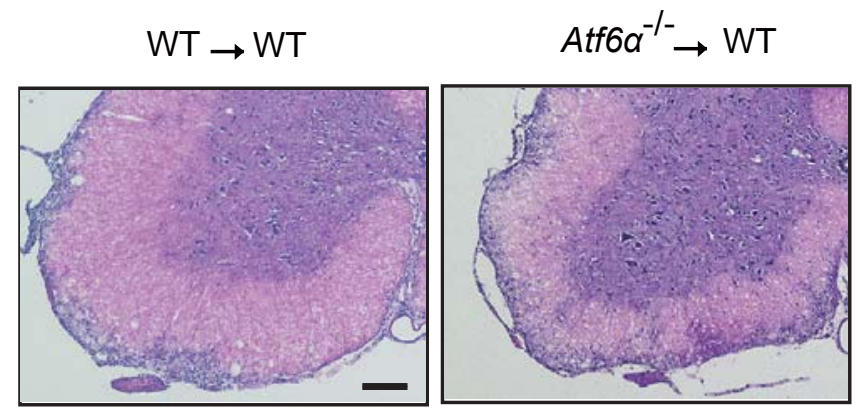

Fig. 4 
A
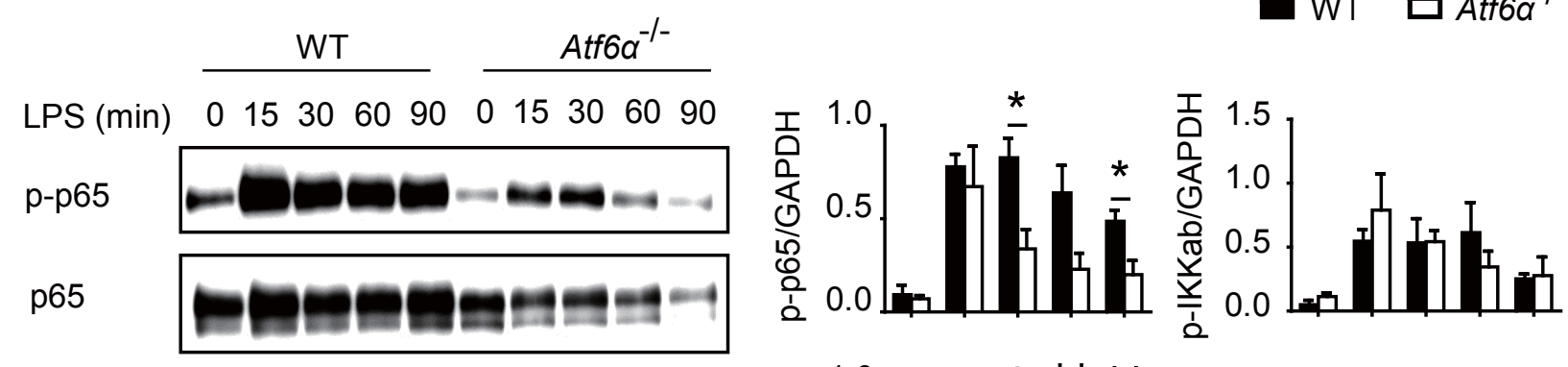

$\mathrm{p}-\mathrm{IKK} \alpha / \beta$

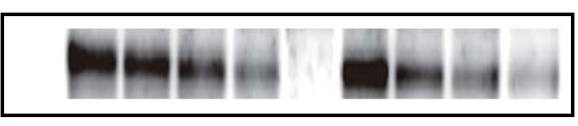

$\mathrm{I} \kappa \mathrm{B} \alpha$

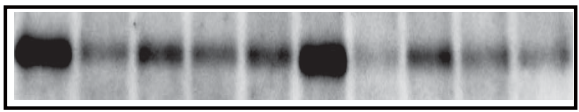

GAPDH
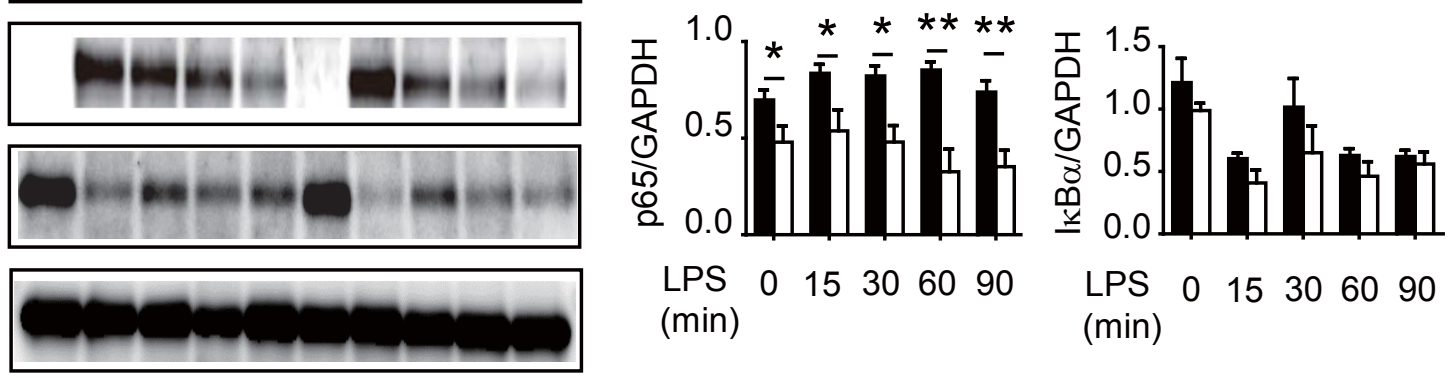

$\begin{array}{llllll}\text { LPS } & 0 & 15 & 30 & 60 & 90\end{array}$ (min)

LPS $\quad 0 \quad 15 \quad 3060 \quad 90$ (min)

B

WT
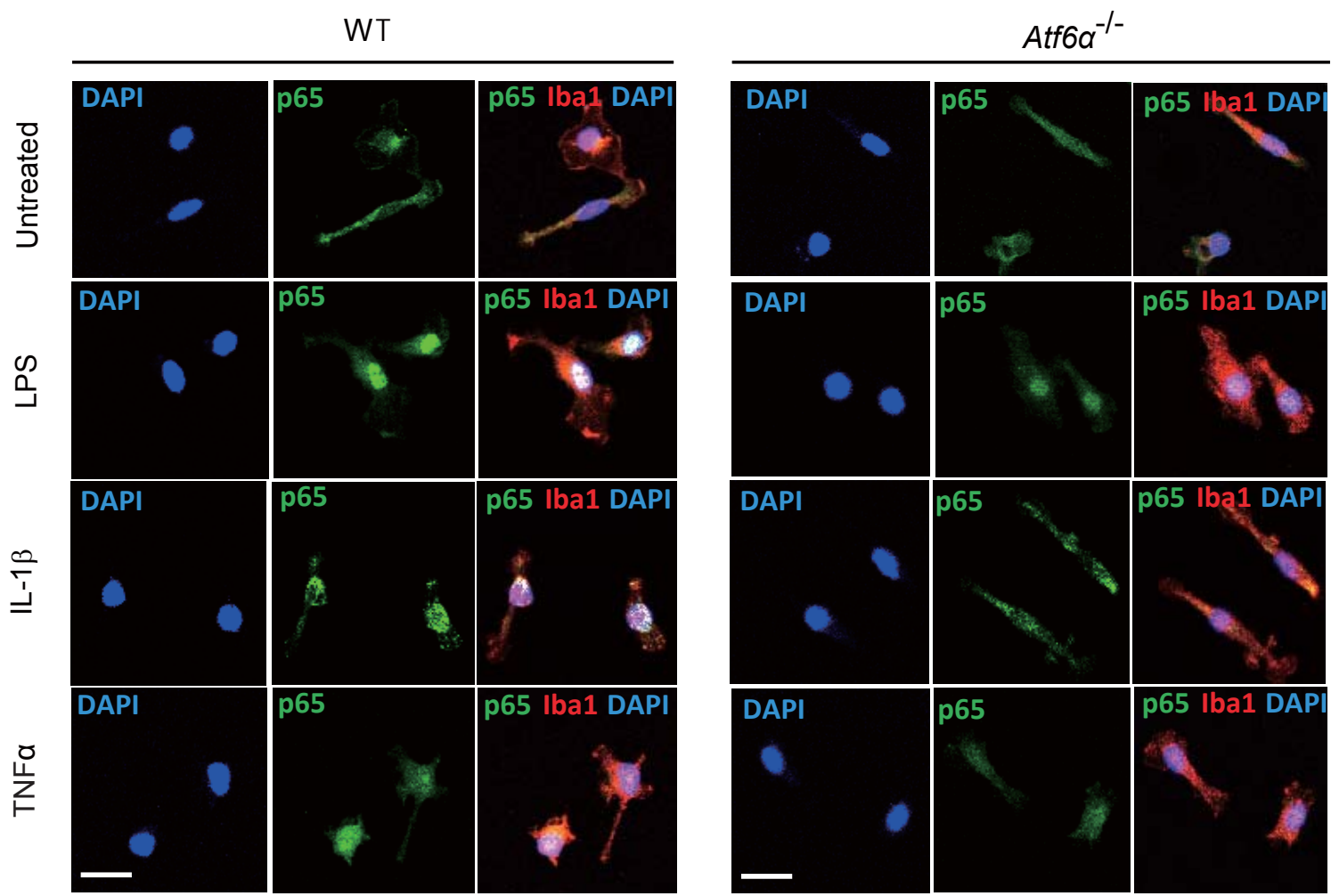

C

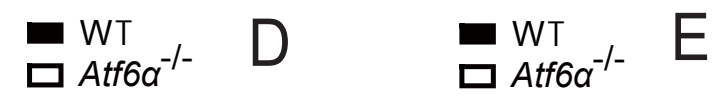

E

- WT

口Atf6a $a^{-/-}$
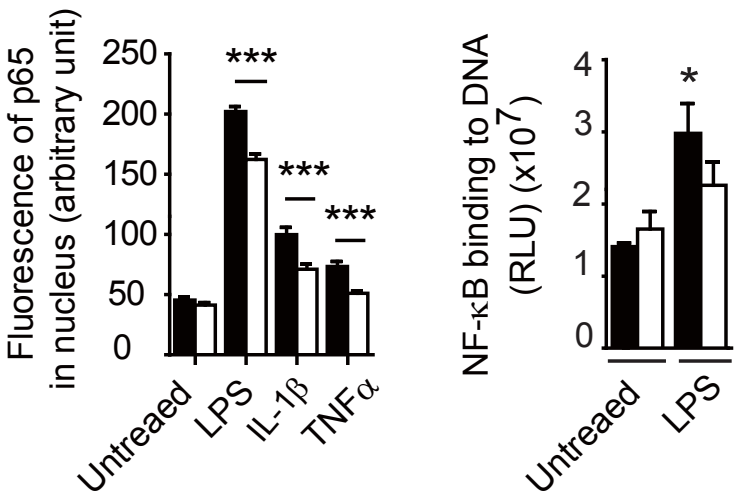

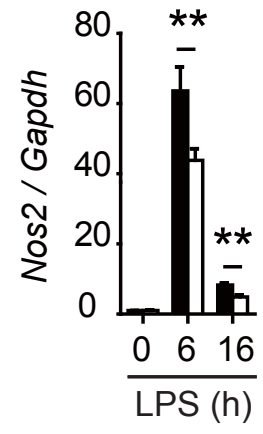
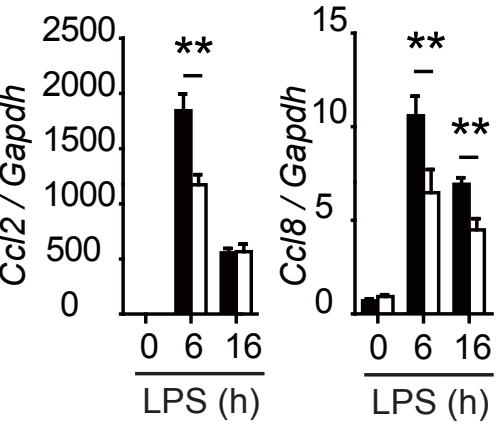

Fig. 5 

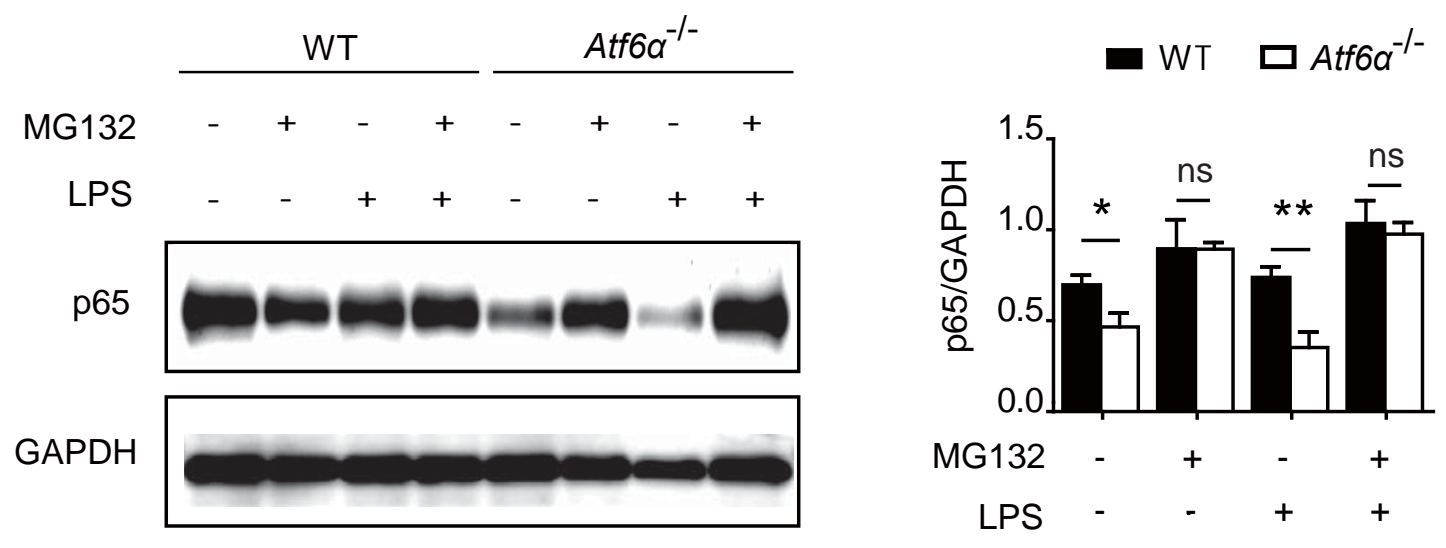

Fig. 6 


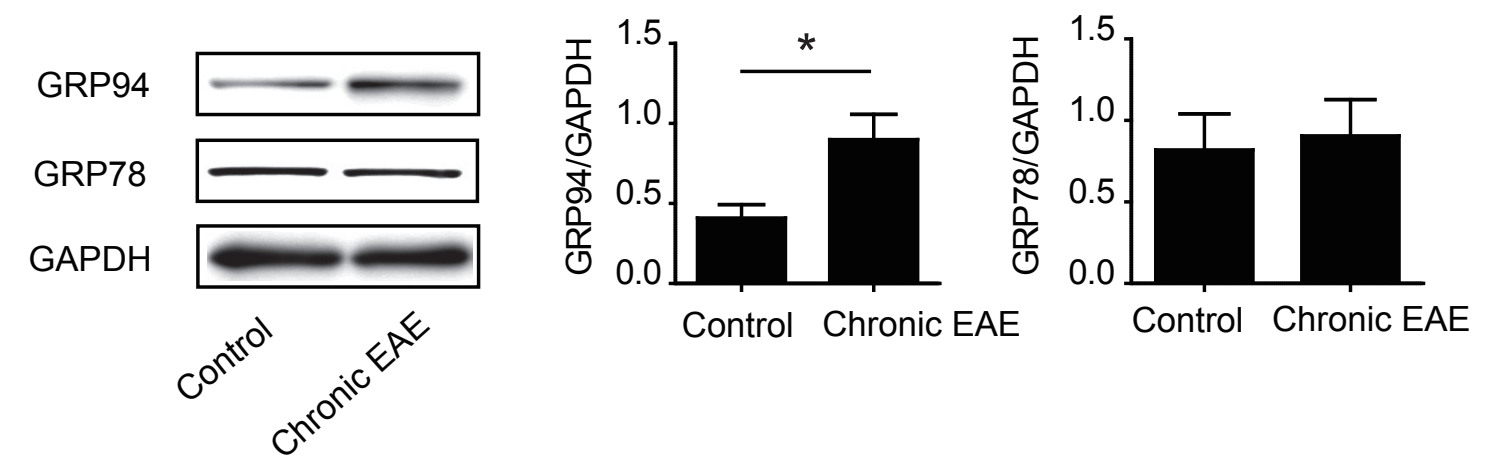

Fig. S1 
A

WT

口 Atf6a $\alpha^{-/-}$
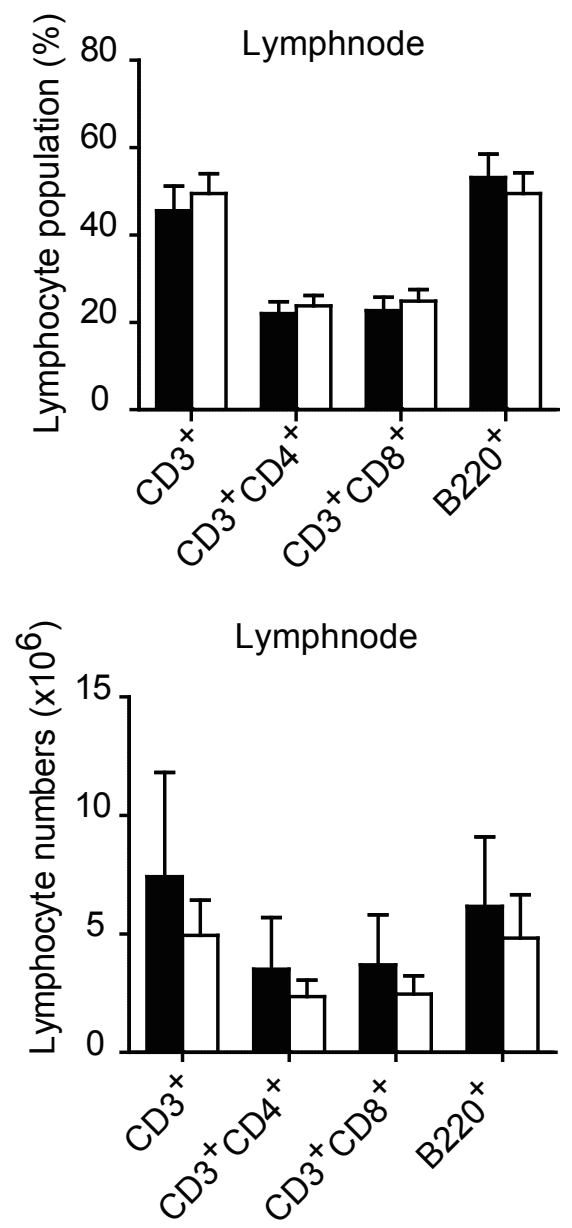

C

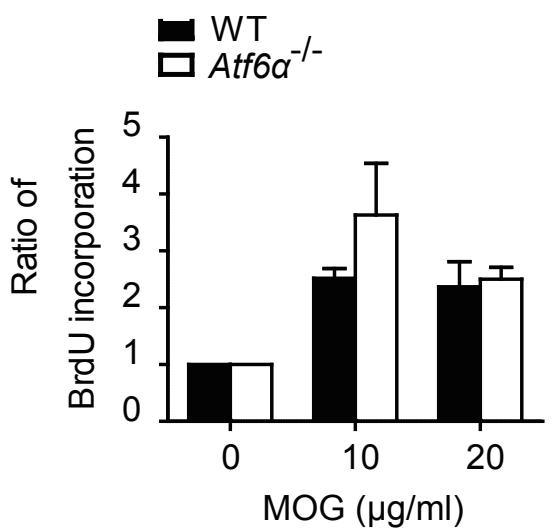

B

WT

口 $A T F 6 \alpha^{-/-}$
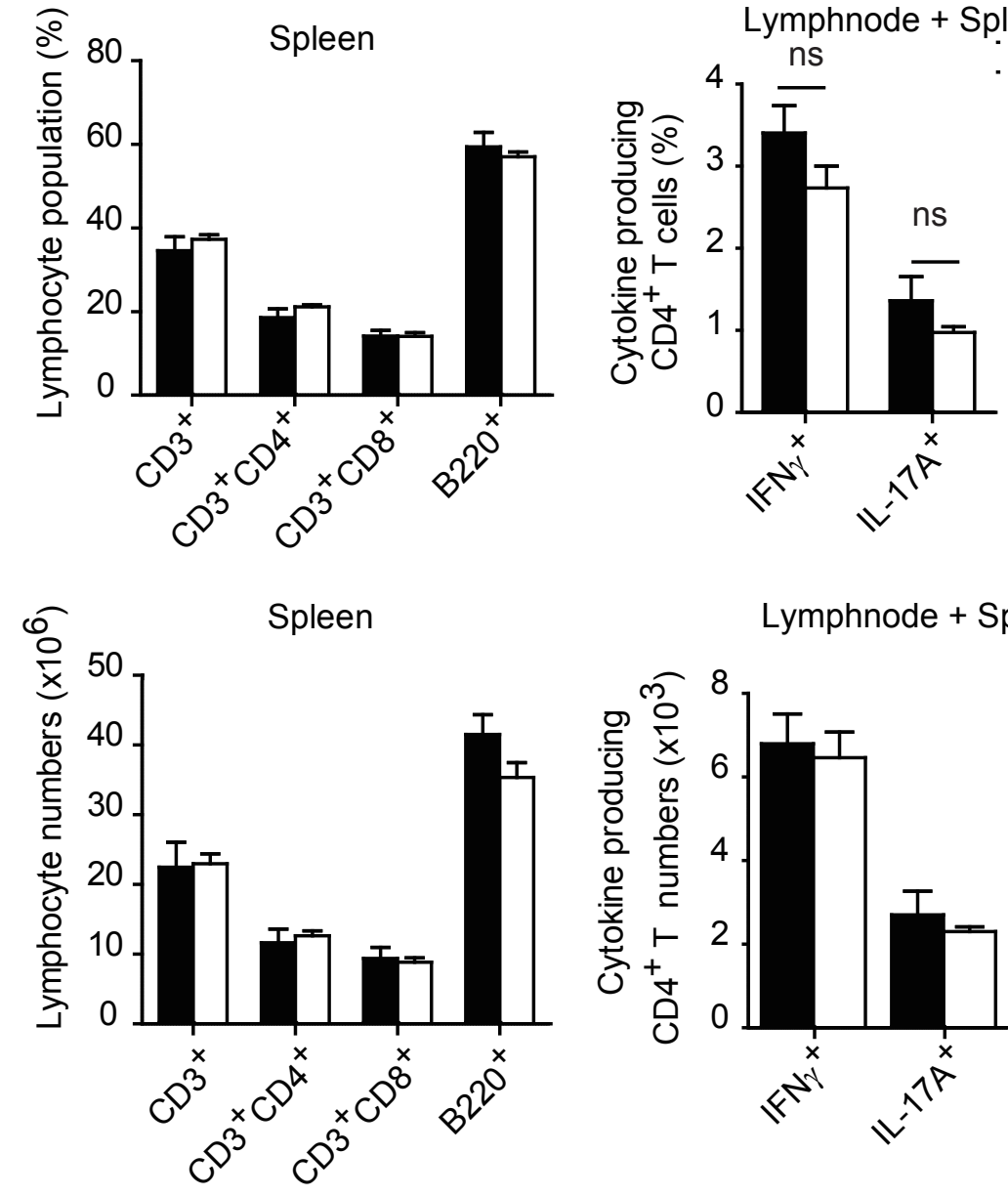

Lymphnode + Spleen

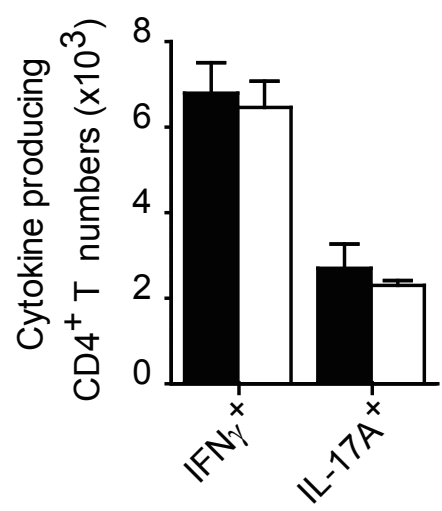

Fig. S2 
A
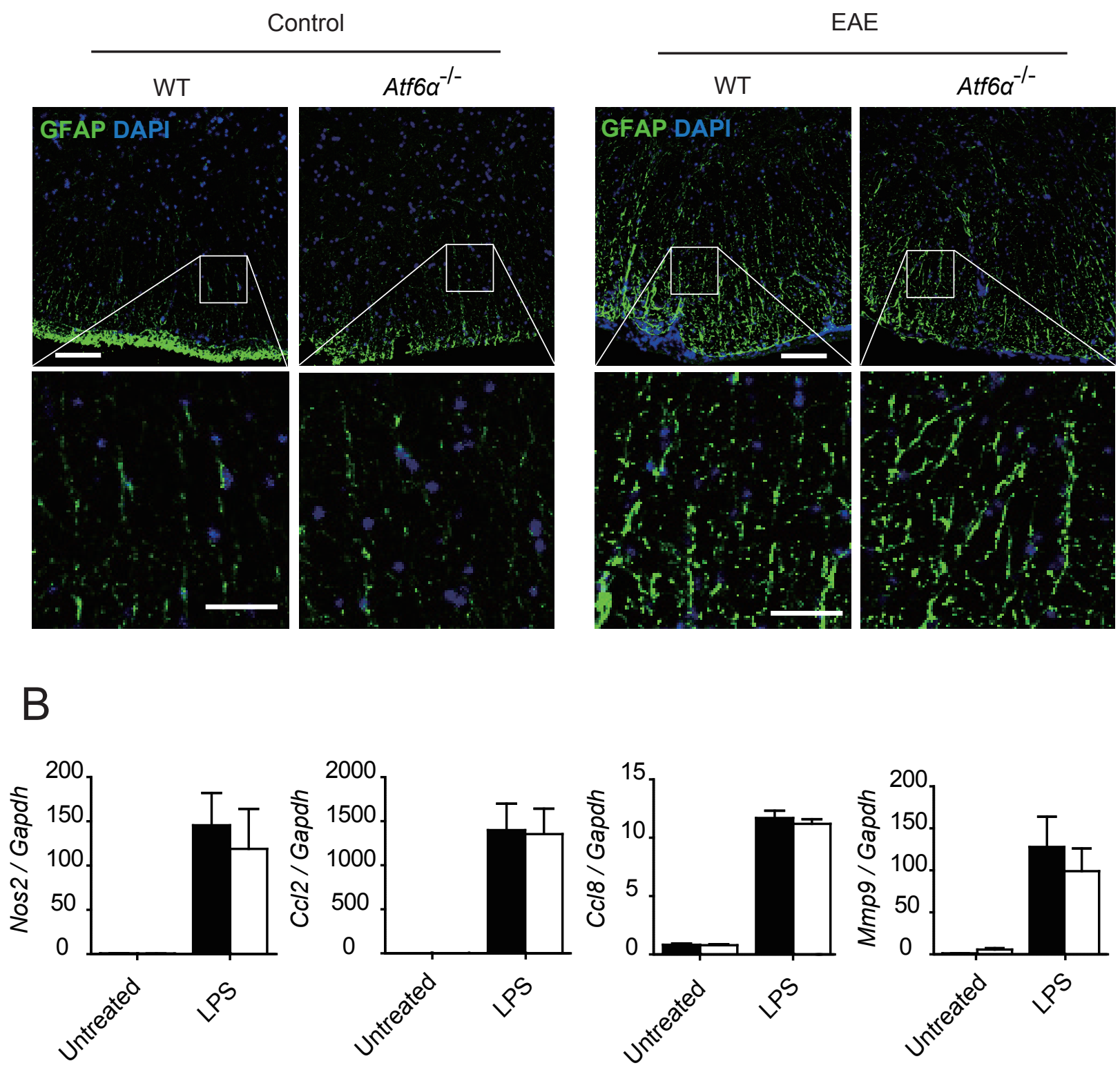

Fig. S3 
A
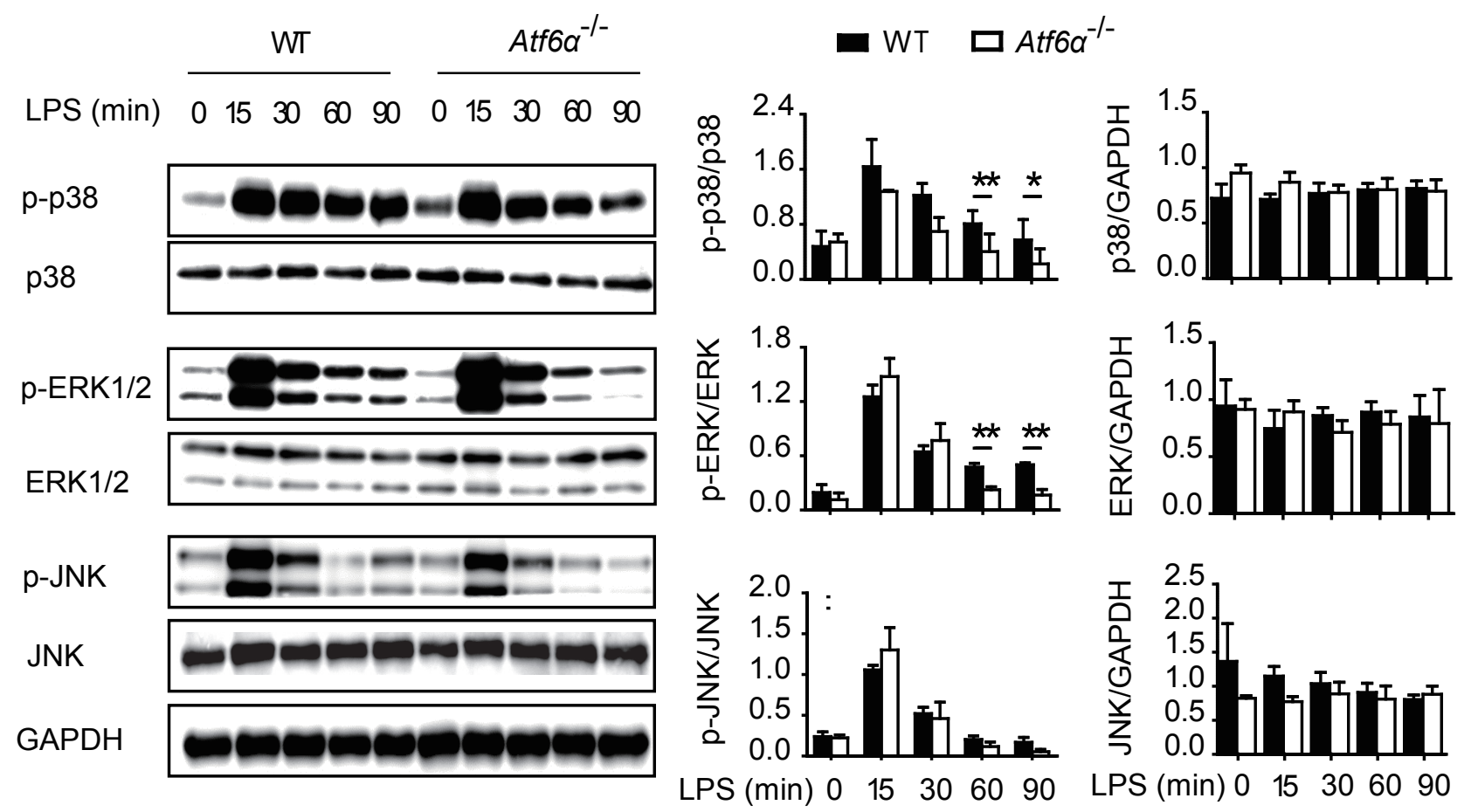

B

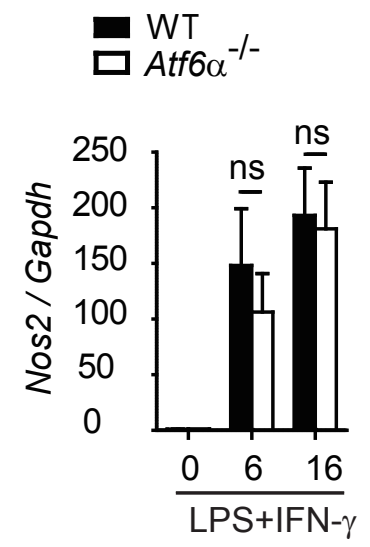

(h)

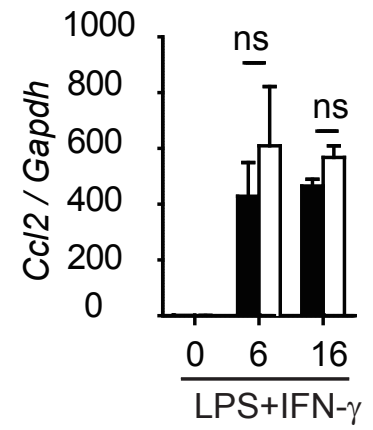

(h)

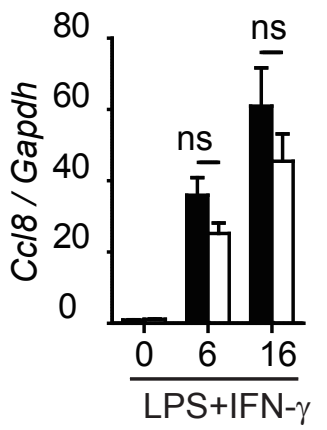

(h)
Fig S4 


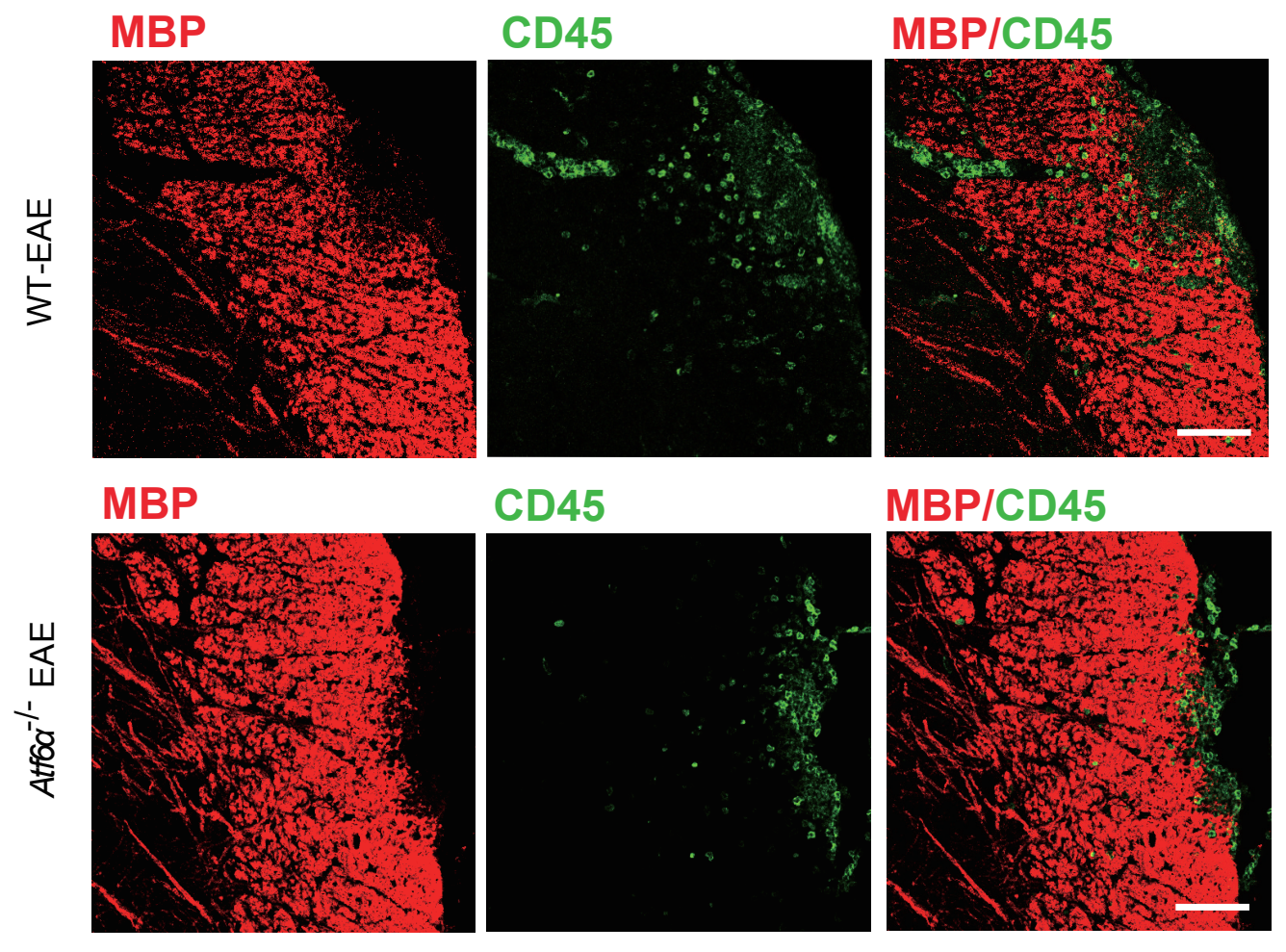

Fig. S5 